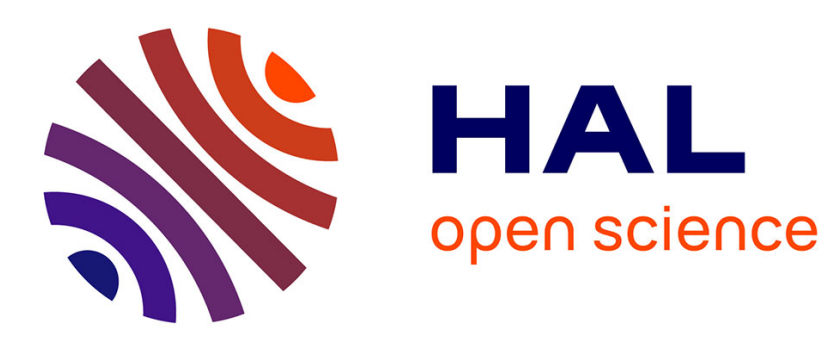

\title{
Cost-Volume-Profit analysis under uncertainty: A model with fuzzy estimators based on confidence intervals
}

\author{
Konstantinos A. Chrysafis, Basil K. Papadopoulos
}

\section{To cite this version:}

Konstantinos A. Chrysafis, Basil K. Papadopoulos. Cost-Volume-Profit analysis under uncertainty: A model with fuzzy estimators based on confidence intervals. International Journal of Production Research, 2009, 47 (21), pp.5977-5999. 10.1080/00207540802112660 . hal-00513037

\section{HAL Id: hal-00513037 \\ https://hal.science/hal-00513037}

Submitted on 1 Sep 2010

HAL is a multi-disciplinary open access archive for the deposit and dissemination of scientific research documents, whether they are published or not. The documents may come from teaching and research institutions in France or abroad, or from public or private research centers.
L'archive ouverte pluridisciplinaire HAL, est destinée au dépôt et à la diffusion de documents scientifiques de niveau recherche, publiés ou non, émanant des établissements d'enseignement et de recherche français ou étrangers, des laboratoires publics ou privés. 


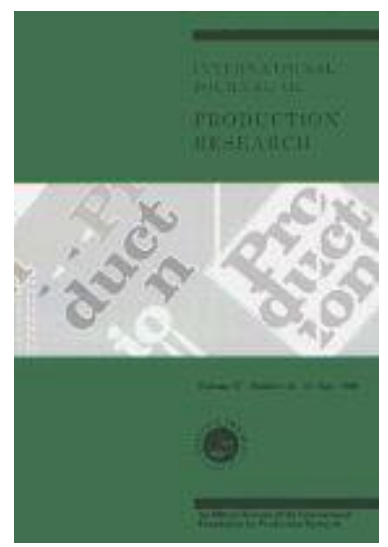

Cost-Volume-Profit analysis under uncertainty: A model with fuzzy estimators based on confidence intervals

\begin{tabular}{|r|l|}
\hline Journal: & International Journal of Production Research \\
\hline Manuscript ID: & TPRS-2008-IJPR-0191 \\
\hline Manuscript Type: & Original Manuscript \\
\hline Author: & 04-Mar-2008 \\
\hline Complete List of Authors: & $\begin{array}{l}\text { Chrysafis, Konstantinos; Democritus University of Thrace, Civil } \\
\text { Engineering } \\
\text { Papadopoulos, Basil; Democritus University of Thrace, Civil } \\
\text { Engineering }\end{array}$ \\
\hline Keywords: & $\begin{array}{l}\text { COST ANALYSIS, COST ESTIMATING, FUZZY LOGIC, FUZZY } \\
\text { METHODS, STATISTICAL METHODS }\end{array}$ \\
\hline Keywords (user): & $\begin{array}{l}\text { Cost-Volume-Profit Analysis, Breakeven Analysis, Decision making, } \\
\text { Risk Management, Fuzzy Estimators, Fuzzy Sets }\end{array}$ \\
\hline \multicolumn{2}{|l}{} \\
\hline
\end{tabular}

\section{S) ScholarONE" \\ Manuscript Central}




\title{
Cost-Volume-Profit analysis under uncertainty: A model with fuzzy estimators based on confidence intervals
}

\author{
Konstantinos A. Chrysafis, Basil K. Papadopoulos ${ }^{1}$
}

\author{
Democritus University of Thrace, School of Engineering, \\ Department of Civil Engineering, Section of Mathematics, Xanthi 67100, Greece
}

\begin{abstract}
In this paper we express the uncertainty existing in CVP analysis via a new method which constructs fuzzy estimators for the parameters of a given probability distribution function, using statistical data. Firstly we present a fuzzy function for the cost and we search for the optimal solution among alternatives as Finch and Gavirneni (2006) do, but here we use fuzzy estimators for the variable costs. As a consequence, we formulate a fuzzy number which represents the difference between the costs of the alternatives. Furthermore, we consider conditions of "complete" uncertainty when a company needs to chose between two products and we express the profits and the risk via fuzzy estimators. Finally in the same conditions of uncertainty we express the breakeven point when the income equals the total cost.
\end{abstract}

Keywords: Cost-Volume-Profit Analysis, Breakeven Analysis, Decision making, Risk Management, Fuzzy Estimators, Fuzzy Sets

\section{Introduction}

Breakeven analysis, or often referred to as cost-volume-profit analysis, can illustrate a great number of business decisions. In general the breakeven analysis can be used in three different manners. It can be used in decisions which concern new products by contributing in the definition of the sales level of this new product that is indicated for the realization of profit. It can also be used as a tool for the research of sequences of an increase in the products volume. Finally it can be used in modernization and automatization programs, with the aid of which the company will continuously replace variable costs with fixed ones.

Traditional breakeven analysis obeys to some limiting assumptions [Chan et al. (1990), Gonzales (2001), Jaedecke et al. 1964]. Some of the most important are the following: It assumes that the total cost can be analyzed in fixed and variable cost. The fixed cost remains the same during the analysis. The variable cost changes proportionally to the volume. The price of the product remains the same during the analysis. The profits and the costs can both be analyzed in relation with the volume. But are always all of these assumptions effective? Let us consider a company which wants to choose between products A and B. Each of them can be produced in the currents plants and demands an increase in the fixed cost of the company of 600.000USD. The contribution margin is 4USD. According to this data the breakeven point for both products is 150.000 units. So the company cannot decide which of these two products to choose. In other words the traditional breakeven analysis gives the company the capability to compute the breakeven point of each product, but it cannot discriminate between the two products. This weakness is due to the fact that the

Email adresses: kgoldenfme@hotmail.com (K. Chrysafis) papadob@civil.duth.gr (B. Papadopoulos) 
traditional breakeven analysis assumes cost (fixed and variable) price and volume as certain variables. In fact they are random. By considering these variables as random the uncertainty is introduced in breakeven analysis.

Here we propose a completely new method implemented by Chrysafis and Papadopoulos (2008) in the field of financial engineering and initially presented by Papadopoulos and Sfiris (submitted for publication). It concerns a new method of constructing fuzzy estimators for the parameters of a given probability distribution function, using statistical data. In statistics, as we know, there is the point estimation of a parameter. But this is not enough for us to derive safe conclusions. That's why statistics introduce confidence intervals. The disadvantage of confidence intervals is that we have to choose the probability so that the parameter for estimation to be in this interval. With this methodology and by making use of the tool of fuzzy numbers we define fuzzy estimators for any estimated parameter, using the confidence intervals. The fuzzy number that results is considered to be the statistical estimator that expresses a degree of an unbiased estimation. The motivation is the following: We wonder if the confidence intervals for the mean $\mu$ are the $\alpha$-cuts of a fuzzy number A. The question that arises is: What does this fuzzy number depict? In other words, if $\mathrm{x}$ is a number, what does the membership value $\mathrm{A}(\mathrm{x})$ express? The answer is that the membership value $\mathrm{A}(\mathrm{x})$ expresses "a degree of unbiased estimation".

Since now many efforts have been realized in studying breakeven analysis under uncertainty. In J. and P. Yunker (2003), (1982), (2003), they propose a generalized CVP model including both demand and average cost functions and incorporating very general allowance for stochastic elements. They develop the relationship between expected profit and breakeven probability in the general model. Then in they analyze and apply a CVP under uncertainty model specifically geared toward classroom instruction. It is a simpler model than many of those developed in the research literature, but it does incorporate one advanced component: an "economic" demand function relating the expected sales level to price. In R. Ravichandran (1993), the author presents a decision support system for applying cost-volume-profit analysis in an uncertain environment. He considers a decision support system for applying cost-volume-profit analysis in an uncertain environment. Product mix programming problem is considered when the contributions of the products are stochastic in nature. Jaedecke and Robicheck (1964) provided the seminal work regarding CVP analyses' lack of inclusion of uncertainty. That work, along with others Dickinson (1974), Badr and Loudeback (1979), Shih ((1979), Norland (1980), Clarke (1986), Chung (1993) recognized as a major shortfall in the traditional analysis the likelihood that there would be uncertainty regarding much of the information used. Most of the studies focusing on uncertainty with CVP or breakeven analysis have focused on demand uncertainty, probably because the typical uses of the technique involve determining whether an opportunity for profit existed at a projected level of demand [Finch et al. (2006)].

In this paper we extend the traditional breakeven analysis to accommodate situations that the variable cost is uncertain as Finch and Gavirneni (2006) do, but here we make use of fuzzy estimators. Finally we consider conditions of complete uncertainty and we express the breakeven point, in units of product as a fuzzy number by making use of fuzzy estimators for all the variables (fixed cost, variable cost, price, volume). In all of the applications, a numerical example is given for better understanding.

\section{Fuzzy Set Theory}

\subsection{Basic Concepts}

Here we need the following definitions and propositions [Klir, Yan (1995)]:

Definition 2.1: If A is a function from $X$ into the interval $[0,1]$ then $A$ is called a fuzzy set. A is convex iff or every $t \in[0,1]$ and $x_{1}, x_{2} \in X$ we have

$$
A\left(t x_{1}+(1-t) x_{2}\right) \geq \min \left\{A\left(x_{1}\right), A\left(x_{2}\right)\right\}
$$


A is normalized if there exists $x \in X$, such that $A(x)=1$.

Definition 2.2: If $A$ is a fuzzy set, by a-cuts $a \in[0,1]$ we mean the $\operatorname{sets}^{a} A=\{x \in X: A(x) \geq a\}$.

It is known that the a-cuts determine the fuzzy set $A$. Let now $A$ and $B$ denote fuzzy numbers and let * denote any of the four basic arithmetic operations. Then, we define a fuzzy set on $\mathfrak{R}, A^{*} B$, by defining it's a-cut, ${ }^{a}\left(A^{*} B\right)$ as

$$
{ }^{a}\left(A^{*} B\right)={ }^{a} A^{* a} B
$$

for any $a \in(0,1]$.

Definition 2.3: We say that $A$ is a fuzzy number if the following conditions hold:

1. $A$ is normal,

2. $A$ is a convex fuzzy set,

3. $A$ is upper semicontinuous,

4. The support of $A, \bigcup_{a \in(0,1]}^{a} A=\{x: A(x)>0\}$ is compact.

Then the a-cuts of $A$ are closed intervals. We also know that if ${ }^{a} A={ }^{a} B \quad \forall a \in[0,1]$ for arbitrary fuzzy sets $A$ and $B$ then $A=B$.

For the realization of the operations we use Nguyen's (1978) propositions.

Proposition 2.1: Let $f: X x Y \rightarrow Z$, and $A \in P(X), B \in P(Y)$ then:

$$
f(A, B)=\int_{0}^{1} a f\left({ }^{a} A,{ }^{a} B\right) d a
$$

Proposition 2.2: With the notation of the proposition 2.1 and If $f: \mathfrak{R} \times \mathfrak{R} \rightarrow \mathfrak{R}$ is continuous then, $\forall A, B \in P(\Re, S, K)$ and we have:

$$
\left[f^{a}(A, B)\right]=f\left({ }^{a} A,{ }^{a} B\right) \quad \forall a \in[0,1]
$$

if $\forall z \in Z, \sup _{(x, y) \in f^{-1}(x)}\left[\mu_{\mathrm{A}}(x) \wedge \mu_{A}(y)\right]$ is attained.

We also mention that the a-cut of a fuzzy number $A$ can be written as an interval of this form:

$$
{ }^{a} A=\left[{ }^{a} A_{l},{ }^{a} A_{r}\right]
$$

\subsection{Arithmetic operations on Intervals}

Fuzzy arithmetic is based on two properties of fuzzy numbers [Klir, Yan (1995)]: 
Property 1: each fuzzy set and thus also each fuzzy number, can fully and uniquely be represented by its acuts

Property 2: a-cuts of each fuzzy number are closed intervals of real numbers for all $a \in(0,1]$.

These properties, enable us to define arithmetic operations on fuzzy numbers, in terms of arithmetic operations on their a-cuts. The latter operations are a subject of interval analysis, a well-established area of classical mathematics.

Let $*$ denote any of the four arithmetic operations on closed intervals: addition + , subtraction -, multiplication ', division /. Then:

$$
[a, b]^{*}[d, e]=\left[f^{*} g \mid a \leq f \leq b, d \leq g \leq e\right]
$$

is a general property of all arithmetic operations on closed intervals, except that $[a, b] /[d, e]$ is not defined when $0 \in[d, e]$. That is, the result of an arithmetic operation on closed intervals is again a closed interval.

The four arithmetic operations on closed intervals are defined as follows:

$$
\begin{gathered}
{[a, b]+[d, e]=[a+d, b+e]} \\
{[a, b]-[d, e]=[a-e, b-d]} \\
{[a, b] \cdot[d, e]=[\min \{a d, a e, b d, b e\}, \max \{a d, a e, b d, b e\}],} \\
\text { provided that } 0 \notin[d, e] . \text { If a }, \mathrm{b}, \mathrm{c}, \mathrm{d}>0 \text { then }[a, b] \cdot[d, e]=[a d, b e] \\
{[a, b] /[d, e]=[a, b] \cdot\left[\frac{1}{d}, \frac{1}{e}\right]=\left[\min \left\{\frac{a}{d}, \frac{a}{e}, \frac{b}{d}, \frac{b}{e}\right\}, \max \left\{\frac{a}{d}, \frac{a}{e}, \frac{b}{d}, \frac{b}{e}\right\}\right]} \\
\text { provided that } 0 \notin[d, e]
\end{gathered}
$$

Note that a real number $r$ may also be regarded as a special (degenerated) interval $[r, r]$. When one of the above intervals is degenerated, we obtain special operations; when both of them are degenerated we obtain the standard arithmetic of real numbers.

\section{Non-Asymptotic Fuzzy Estimators Based on Confidence Intervals}

Here we present the method implemented by Chrysafis and Papadopoulos (2008) in the field of financial engineering and initially presented by Papadopoulos and Sfiris:

Proposition 4.1: Let $\mathrm{X}_{1}, \mathrm{X}_{2}, \ldots, \mathrm{X}_{n}$ be a random sample and let $x_{1}, x_{2}, \ldots x_{n}$ be sample values assumed by the sample. Let also $\beta \in[0,1)$. If the sample size is large enough, then

$$
M(x)=\left\{\begin{array}{lll}
\frac{2}{1-\beta} \Phi\left(\frac{x-\bar{x}}{\sigma / \sqrt{n}}\right)-\frac{\beta}{1-\beta} & \text { if } & \bar{x}-\frac{\sigma}{\sqrt{n}} \Phi^{-1}\left(1-\frac{\beta}{2}\right) \leq x \leq \bar{x} \\
\frac{2}{1-\beta} \Phi\left(\frac{\bar{x}-x}{\sigma / \sqrt{n}}\right)-\frac{\beta}{1-\beta} & \text { if } & \bar{x} \leq x \leq \bar{x}+\frac{\sigma}{\sqrt{n}} \Phi^{-1}\left(1-\frac{\beta}{2}\right)
\end{array}\right.
$$


is a fuzzy number, the base of which is exactly the $1-\beta$ confidence interval for $\mu$ and the $\alpha$-cuts of this fuzzy number are the closed intervals:

$$
{ }^{\alpha} M=\left[\bar{x}-z_{g(\alpha)} \frac{\sigma}{\sqrt{n}}, \bar{x}+z_{g(\alpha)} \frac{\sigma}{\sqrt{n}}\right]
$$

which are exactly the $(1-a)(1-\beta)$ confidence intervals for $\mu$.

Where

$$
g(\alpha)=\left(\frac{1}{2}-\frac{\beta}{2}\right) \alpha+\frac{\beta}{2}, \quad\left(g:[0,1] \rightarrow\left[\frac{\beta}{2}, 0.5\right]\right)
$$

and

$$
z_{g(\alpha)}=\Phi^{-1}(1-g(\alpha))
$$

Proposition 4.2: Let $\mathrm{X}$ be a random variable and $x_{1}, x_{2}, \ldots x_{n}$ be observations on $\mathrm{X}$. Let also $\beta \in[0,1)$. If the sample size is large enough, then

$$
M(x)=\left\{\begin{array}{l}
\frac{2-\beta}{1-\beta}-\frac{2}{1-\beta} \Phi\left(\sqrt{\frac{n-1}{2}}\left(\frac{s^{2}}{x}-1\right)\right) \text { if } \frac{s^{2}}{1+\Phi^{-1}\left(1-\frac{\beta}{2}\right) \sqrt{\frac{2}{n-1}}} \leq x \leq s^{2} \\
\frac{2-\beta}{1-\beta}-\frac{2}{1-\beta} \Phi\left(\sqrt{\frac{n-1}{2}}\left(1-\frac{s^{2}}{x}\right)\right) \text { if } s^{2} \leq x \leq \frac{s^{2}}{1-\Phi^{-1}\left(1-\frac{\beta}{2}\right) \sqrt{\frac{2}{n-1}}}
\end{array}\right.
$$

is a fuzzy number, the base of which is exactly the $1-\beta$ confidence interval for $s^{2}$ and the $\alpha$-cuts of this fuzzy number are the closed intervals:

$$
{ }^{\alpha} M=\left[\frac{s^{2}}{1+z_{g(\alpha)} \sqrt{\frac{2}{n-1}}}, \frac{s^{2}}{1-z_{g(\alpha)} \sqrt{\frac{2}{n-1}}}\right]
$$

which are exactly the $(1-a)(1-\beta)$ confidence intervals for $s^{2}$.

Where

$$
g(\alpha)=\left(\frac{1}{2}-\frac{\beta}{2}\right) \alpha+\frac{\beta}{2}, \quad\left(g:[0,1] \rightarrow\left[\frac{\beta}{2}, 0.5\right]\right)
$$

and

$$
z_{g(\alpha)}=\Phi^{-1}(1-g(\alpha))
$$


Proposition 4.3: Let $\mathrm{X}_{1}, \mathrm{X}_{2}, \ldots, \mathrm{X}_{n}$ be a random sample and let $x_{1}, x_{2}, \ldots x_{n}$ be sample values assumed by the sample. Let also $\beta \in[0,1)$. If the sample size is small, then

$$
M(x)=\left\{\begin{array}{lll}
\frac{2}{1-\beta} F\left(\frac{x-\bar{x}}{s / \sqrt{n}}\right)-\frac{\beta}{1-\beta} \text { if } & \bar{x}-F^{-1}\left(\frac{1-\beta}{2}\right) \leq x \leq \bar{x} \\
\frac{2}{1-\beta} F\left(\frac{x-\bar{x}}{s / \sqrt{n}}\right)-\frac{\beta}{1-\beta} \text { if } \quad \bar{x} \leq x \leq \bar{x}+F^{-1}\left(\frac{1-\beta}{2}\right)
\end{array}\right.
$$

is a fuzzy number, the base of which is exactly the $1-\beta$ confidence interval for $\mu$ and the $\alpha$-cuts of this fuzzy number are the closed intervals:

$$
{ }^{a} M=\left[\bar{x}-t_{g(a)} \frac{s}{\sqrt{n}}, \bar{x}+t_{g(a)} \frac{s}{\sqrt{n}}\right]
$$

which are exactly the $(1-\alpha)(1-\beta)$ confidence intervals for $\mu$.

Where

$$
g(a)=\left(\frac{1}{2}-\frac{\beta}{2}\right) \alpha+\frac{\beta}{2}, \quad\left(g:[0,1] \rightarrow\left[\frac{\beta}{2}, 0.5\right]\right)
$$

and

$$
t_{g(\alpha)}=F^{-1}(1-g(\alpha))
$$

Proposition 4.4: Let $\mathrm{X}_{1}, \mathrm{X}_{2}, \ldots, \mathrm{X}_{n}$ be a random sample and let $x_{1}, x_{2}, \ldots x_{n}$ be sample values assumed by the sample. Let also $\beta \in[0,1)$. If the sample size is small, then

$$
M(x)=\left\{\begin{array}{lc}
\frac{2-\beta}{1-\beta}-\frac{2}{1-\beta} F\left(\frac{(n-1) s^{2}}{x}\right) \text { if } \frac{(n-1) s^{2}}{F^{-1}\left(\frac{\beta}{2}\right)} \leq x \leq \frac{(n-1) s^{2}}{F^{-1}\left(\frac{1}{2}\right)} \\
-\frac{2-\beta}{1-\beta}+\frac{2}{1-\beta} F\left(\frac{(n-1) s^{2}}{x}\right) \text { if } \frac{(n-1) s^{2}}{F^{-1}\left(\frac{1}{2}\right)} \leq x \leq \frac{(n-1) s^{2}}{F^{-1}\left(\frac{2-\beta}{2}\right)}
\end{array}\right.
$$

is a fuzzy number, the base of which is exactly the 1- $\beta$ confidence interval for $s^{2}$ and the $\alpha$-cuts of this fuzzy number are the closed intervals:

$$
{ }^{a} M=\left[\frac{(n-1) s^{2}}{x_{g(a)}^{2}}, \frac{(n-1) s^{2}}{x_{1-g(a)}^{2}}\right]
$$


which are exactly the $(1-\alpha)(1-\beta)$ confidence intervals for $s^{2}$.

Where

$$
g(a)=\left(\frac{1}{2}-\frac{\beta}{2}\right) \alpha+\frac{\beta}{2}, \quad\left(g:[0,1] \rightarrow\left[\frac{\beta}{2}, 0.5\right]\right)
$$

and

$$
x_{g(\alpha)}^{2}=F^{-1}(1-g(\alpha))
$$

\section{Fuzzy Estimators for low-cost alternatives in breakeven analysis}

We consider two alternatives, (A) and (B), with the following cost structures [Finch, Gavirneni (2006)]:

$$
\begin{aligned}
& C_{A}(n)=F_{A}+V_{A} n \\
& C_{B}(n)=F_{B}+V_{B} n
\end{aligned}
$$

C: cost, F: Fixed Cost, V: Variable Cost, n: Production volume

An assumption implicit in these equations is that once variable cost has been realized, it applies to all the units in the production volume [Finch, Gavirneni (2006)].

Let us now consider the difference between these alternatives which will help us derive which alternative is

$$
D(n)=C_{A}(n)-C_{B}(n)=F_{A}-F_{B}+\left(V_{A}-V_{B}\right) n=F_{A}-F_{B}+V_{D} n \quad \text { [Finch, Gavirneni }
$$

In Finch, Gavirneni (2006) the authors mention that variable costs are often projections of future cost per unit and are comprised of such costs as labour, materials, utilities, etc., which can be difficult to predict and subject to inflation or other environmental factors. Variable costs include such product-specific issues as inspection costs, rework costs and scrap costs [Lin and Chang (2002)] as well as maintenance costs [Sheu and Krajewski (1993)] Research devoted to the impact of learning curves often focuses on its effects on variable costs [Finch and Luebbe (1995), Smunt (1999)].

Thus we consider the variable cost as a random variable thus we can estimate its expected price. Here we do that by using the fuzzy estimators.

It holds that if a random variable $Y=a_{1} X_{1}-a_{2} X_{2}$ then $E(Y)=a_{1} E\left(X_{1}\right)-a_{2} E\left(X_{2}\right)$, thus

$$
D(n)=F_{A}-F_{B}+\left[E\left(V_{A}\right)-E\left(V_{B}\right)\right] n \leftrightarrow E(D(n))=F_{A}-F_{B}+E\left(V_{D}\right) n
$$

Let us now consider the fuzzy estimators for the variable cost of the alternatives A and B. Here we will consider that the sample is large. Thus for our computations we will use propositions 1, 2 (we can do exactly the same process if we consider that the sample is small by using propositions 3,4 ). 


$$
\begin{aligned}
& E_{V A}(x)= \begin{cases}\frac{2}{1-\beta} \Phi\left(\frac{x-v_{A}}{\sigma_{V A} / \sqrt{n_{V A}}}\right)-\frac{\beta}{1-\beta} \text { if } & v_{A}-\frac{\sigma_{V A}}{\sqrt{n_{V A}}} \Phi^{-1}\left(1-\frac{\beta}{2}\right) \leq x \leq v_{A} \\
\frac{2}{1-\beta} \Phi\left(\frac{v_{A}-x}{\sigma_{V A} / \sqrt{n_{V A}}}\right)-\frac{\beta}{1-\beta} \text { if } & v_{A} \leq x \leq v_{A}+\frac{\sigma_{V A}}{\sqrt{n_{V A}}} \Phi^{-1}\left(1-\frac{\beta}{2}\right)\end{cases} \\
& E_{V B}(x)=\left\{\begin{array}{lll}
\frac{2}{1-\beta} \Phi\left(\frac{x-v_{B}}{\sigma_{V B} / \sqrt{n_{V B}}}\right)-\frac{\beta}{1-\beta} \text { if } & v_{B}-\frac{\sigma_{V B}}{\sqrt{n_{V B}}} \Phi^{-1}\left(1-\frac{\beta}{2}\right) \leq x \leq v_{B} \\
\frac{2}{1-\beta} \Phi\left(\frac{v_{B}-x}{\sigma_{V B} / \sqrt{n_{V B}}}\right)-\frac{\beta}{1-\beta} & \text { if } & v_{B} \leq x \leq v_{B}+\frac{\sigma_{V B}}{\sqrt{n_{V B}}} \Phi^{-1}\left(1-\frac{\beta}{2}\right)
\end{array}\right.
\end{aligned}
$$

In order to realize the appropriate operations with the fuzzy estimators, we need to find their a-cuts. The acuts of the fuzzy estimators are the following:

$$
\begin{aligned}
& { }^{a} E\left(V_{A}\right)=\left[v_{A}-z_{g(a)} \frac{\sigma_{v A}}{\sqrt{n_{v A}}}, v_{A}+z_{g(a)} \frac{\sigma_{v A}}{\sqrt{n_{v A}}}\right] \\
& { }^{a} E\left(V_{B}\right)=\left[v_{B}-z_{g(a)} \frac{\sigma_{v B}}{\sqrt{n_{v B}}}, v_{B}+z_{g(a)} \frac{\sigma_{v B}}{\sqrt{n_{v B}}}\right]
\end{aligned}
$$

So it results that:

$$
{ }^{a} E\left(V_{D}\right)=\left[v_{A}-z_{g(a)} \frac{\sigma_{v A}}{\sqrt{n_{v A}}}-v_{B}-z_{g(a)} \frac{\sigma_{v B}}{\sqrt{n_{v B}}}, v_{A}+z_{g(a)} \frac{\sigma_{v A}}{\sqrt{n_{v A}}}-v_{B}+z_{g(a)} \frac{\sigma_{v B}}{\sqrt{n_{v B}}}\right]
$$

We consider fuzzy $\bar{D}$ and we take from (1) the following result:

$$
\begin{gathered}
{ }^{a} D_{l}=F_{A}-F_{B}+n v_{A}-n z_{g(a)} \frac{\sigma_{v A}}{\sqrt{n_{v A}}}-n v_{B}-n z_{g(a)} \frac{\sigma_{v B}}{\sqrt{n_{v B}}} \\
{ }^{a} D_{r}=F_{A}-F_{B}+n v_{A}+n z_{g(a)} \frac{\sigma_{v A}}{\sqrt{n_{v A}}}-n v_{B}+n z_{g(a)} \frac{\sigma_{v B}}{\sqrt{n_{v B}}}
\end{gathered}
$$

We now need to find the fuzzy number $\bar{D}$ from its a-cuts. So we have: 


$$
\begin{aligned}
& x=F_{A}-F_{B}+n v_{A}-n z_{g(a)} \frac{\sigma_{v A}}{\sqrt{n_{v A}}}-n v_{B}-n z_{g(a)} \frac{\sigma_{v B}}{\sqrt{n_{v B}}} \leftrightarrow z_{g(a)}=\frac{F_{A}-F_{B}+n v_{A}-n v_{B}-x}{\frac{n \sigma_{v A}}{\sqrt{n_{v A}}}+\frac{n \sigma_{v B}}{\sqrt{n_{v B}}}} \leftrightarrow \\
& \Phi^{-1}(1-g(a))=\frac{F_{A}-F_{B}+n v_{A}-n v_{B}-x}{\frac{n \sigma_{v A}}{\sqrt{n_{v A}}}+\frac{n \sigma_{v B}}{\sqrt{n_{v B}}}} \leftrightarrow g(a)=\Phi\left(\frac{-F_{A}+F_{B}-n v_{A}+n v_{B}+x}{\frac{n \sigma_{v A}}{\sqrt{n_{v A}}+\frac{n \sigma_{v B}}{\sqrt{n_{v B}}}}}\right) \leftrightarrow
\end{aligned}
$$

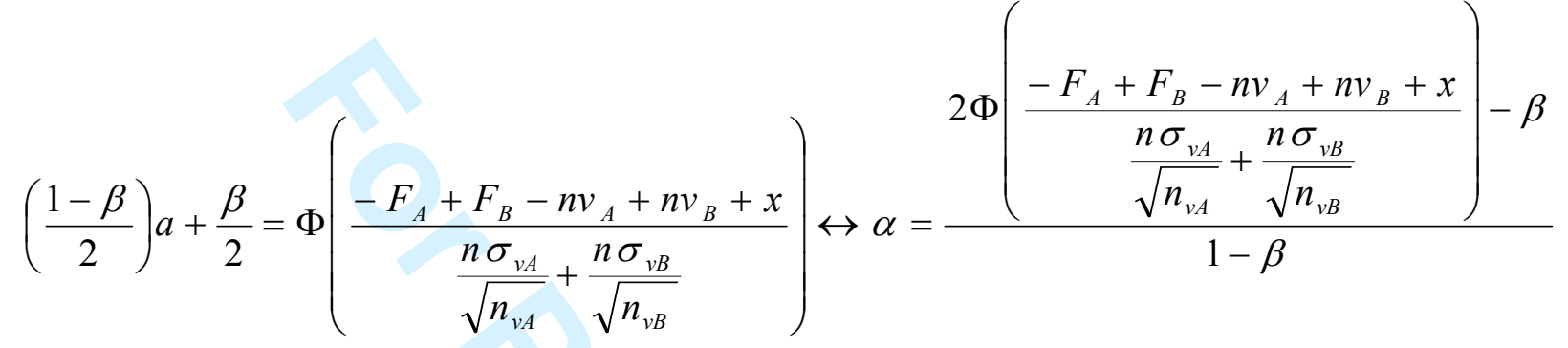

But $a \in[0.1]$ thus we will create the next inequality and we will solve it in order to find $\mathrm{x}$ :

$$
\begin{aligned}
& 0 \leq \frac{2 \Phi\left(\frac{-F_{A}+F_{B}-n v_{A}+n v_{B}+x}{\left.\frac{n \sigma_{v A}}{\sqrt{n_{v A}}+\frac{n \sigma_{v B}}{\sqrt{n_{v B}}}}\right)}\right.}{1-\beta} \leq 1 \leftrightarrow \Phi^{-1}\left(\frac{\beta}{2}\right) \leq \frac{-F_{A}+F_{B}-n v_{A}+n v_{B}+x}{\frac{n \sigma_{v A}}{\sqrt{n_{v A}}}+\frac{n \sigma_{v B}}{\sqrt{n_{v B}}}} \leq 0 \leftrightarrow \\
& \Phi^{-1}\left(\frac{\beta}{2}\right)\left(\frac{n \sigma_{v A}}{\sqrt{n_{v A}}}+\frac{n \sigma_{v B}}{\sqrt{n_{v B}}}\right)+F_{A}-F_{B}+n v_{A}-n v_{B} \leq x \leq F_{A}-F_{B}+n v_{A}-n v_{B}
\end{aligned}
$$

Similarly we derive that

$$
\begin{aligned}
& x=F_{A}-F_{B}+n v_{A}+n z_{g(a)} \frac{\sigma_{v A}}{\sqrt{n_{v A}}}-n v_{B}+n z_{g(a)} \frac{\sigma_{v B}}{\sqrt{n_{v B}}} \leftrightarrow z_{g(a)}=\frac{-F_{A}+F_{B}-n v_{A}+n v_{B}+x}{\frac{n \sigma_{v A}}{\sqrt{n_{v A}}}+\frac{n \sigma_{v B}}{\sqrt{n_{v B}}}} \leftrightarrow \\
& \Phi^{-1}(1-g(a))=\frac{-F_{A}+F_{B}-n v_{A}+n v_{B}+x}{\frac{n \sigma_{v A}}{\sqrt{n_{v A}}}+\frac{n \sigma_{v B}}{\sqrt{n_{v B}}}} \leftrightarrow g(a)=\Phi\left(\frac{F_{A}-F_{B}+n v_{A}-n v_{B}-x}{\frac{n \sigma_{v A}}{\sqrt{n_{v A}}}+\frac{n \sigma_{v B}}{\sqrt{n_{v B}}}}\right) \leftrightarrow
\end{aligned}
$$




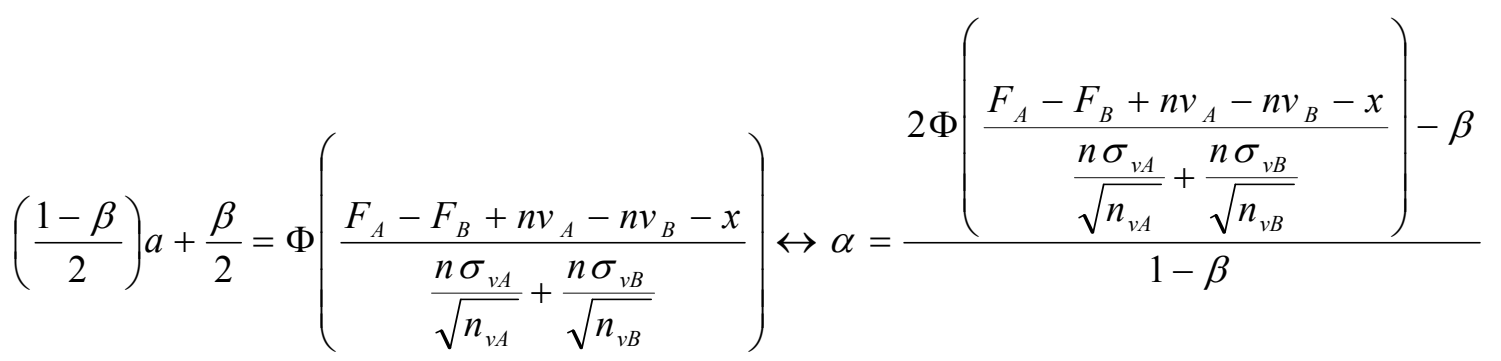

But $a \in[0.1]$ thus:

$$
\begin{aligned}
& 0 \leq \frac{2\left(\frac{F_{A}-F_{B}+n v_{A}-n v_{B}-x}{\frac{n \sigma_{v A}}{\sqrt{n_{v A}}}+\frac{n \sigma_{v B}}{\sqrt{n_{v B}}}}\right)-\beta}{1-\beta} \leq 1 \leftrightarrow \Phi^{-1}\left(\frac{\beta}{2}\right) \leq \frac{F_{A}-F_{B}+n v_{A}-n v_{B}-x}{\frac{n \sigma_{v A}}{\sqrt{n_{v A}}}+\frac{n \sigma_{v B}}{\sqrt{n_{v B}}}} \leq 0 \leftrightarrow \\
& F_{A}-F_{B}+n v_{A}-n v_{B}<x \leq-\Phi^{-1}\left(\frac{\beta}{2}\right)\left(\frac{n \sigma_{v A}}{\sqrt{n_{v A}}}+\frac{n \sigma_{v B}}{\sqrt{n_{v B}}}\right)+F_{A}-F_{B}+n v_{A}-n v_{B}
\end{aligned}
$$

So the fuzzy $\bar{D}$ is the following:

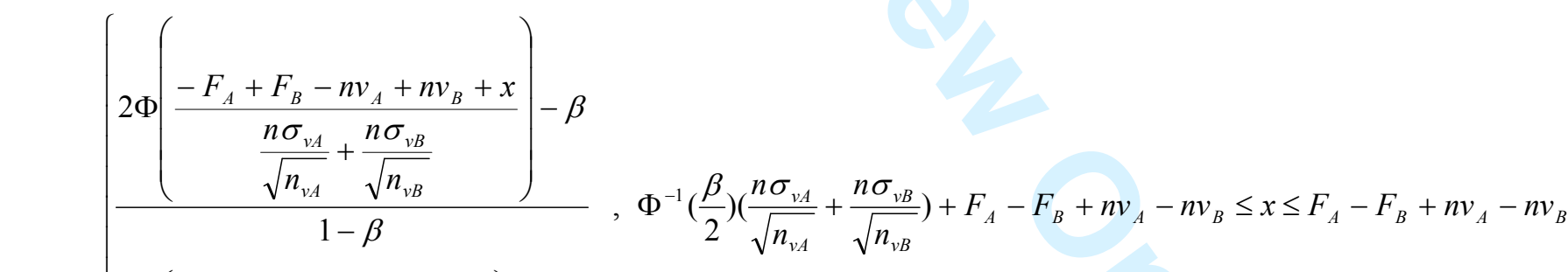

$$
\begin{aligned}
& \bar{D}(x)=\left\{\begin{array}{l}
2 \Phi\left(\frac{F_{A}-F_{B}+n v_{A}-n v_{B}-x}{\left.\frac{n \sigma_{v A}}{\sqrt{n_{v A}}+\frac{n \sigma_{v B}}{\sqrt{n_{v B}}}}\right)-\beta}\right. \\
1-\beta
\end{array}, F_{A}-F_{B}+n v_{A}-n v_{B}<x \leq-\Phi^{-1}\left(\frac{\beta}{2}\right)\left(\frac{n \sigma_{v A}}{\sqrt{n_{v A}}}+\frac{n \sigma_{v B}}{\sqrt{n_{v B}}}\right)+F_{A}-F_{B}+n v_{A}-n v_{B}\right. \\
& 0 \text { otherwise }
\end{aligned}
$$

In Finch, Gavirneni (2006) the authors mention that it is so important, in the process of estimating the cost as a random variable, the selection of the appropriate distribution. In some situations, the distribution 
can be known from experience, in which case the problem is reduced merely to selecting the appropriate parameters [Asiedu et al. (2000)]. But in most situations the distribution is not known and must be determined. The estimation of the variable cost associated with the production of a product, is essentially a forecast of the issues that contribute. In other words they consider the estimation of the expected variable cost as unbiased and the distribution of the error as normal. Thus the distribution of possible variable costs creates a total cost curve that has an expanding range of possible total costs as the production volume increases. They apply 3-sigma limits to that error and in that way they estimate an expected range of possible costs at any given volume. Here we applied fuzzy estimators for the expected value of the random variable. We used propositions 1,2 where we consider that the sample is large. Furthermore, we could use propositions 3,4 if the sample was small. One of the greatest advantages of this method in relation with the most of the existing ones is that we do not need to consider a certain distribution for the random variable, in this instance the cost. Regardless of the fact that we have a large or a small sample we do not need to know the distribution of the sample.

But this is not the most important novelty of this paper. Next, we will see that we realize a more detailed analysis in relation with the existing probabilistic methods, which accommodates the decision making of a company as concerning the production section. As Finch and Gavirneni (2006) do, we also assume that the cost function remains linear and that although there is uncertainty concerning the cost per unit, the cost per unit does not change from unit to unit.

Numerical Example [revisited [Finch, Gavirneni (2006)]p.4336]: Suppose two alternative cost functions A and B. Alternative A has a fixed cost of 35500USD an expected variable cost of 810USD per unit with a standard deviation of 30USD. Alternative A has a fixed cost of 52000USD and an expected variable cost of 330USD per unit with a standard deviation of 25USD with a standard deviation. The number of observations from which we derive the expected variable cost and the standard deviation both for alternatives is $n_{v A}=n_{v B}=36$. Let us depict the curves for the variable cost and also find the fuzzy $\bar{D}$ in order to be able to choose the low cost alternative for different volumes (n).

Solution: In figure (1) we depict the variable cost functions. The $\mathrm{x}$ axis represents the production volume and y axis represents the cost. If we consider the fuzzy estimators for the cost the lines of figure 1 represent their a-cuts and in particular the 0-cut and the 1-cut. The upper three lines depict the alternative A and the lower three lines depict the alternative B. The lower line of the first triple is ${ }^{0} C_{A l}$ (0-cut left tail) and the higher one is ${ }^{0} C_{A r}$ (0-cut right tail). The line between them is the ${ }^{1} C_{A l}={ }^{1} C_{A r}$. The lower line from the other triple is ${ }^{0} C_{B l}$ and the higher one is ${ }^{0} C_{B r}$. The line in the middle is the ${ }^{1} C_{B l}={ }^{1} C_{B r}$. In table 1, we can see the fuzzy estimators for difference between the two alternatives for different values of $\mathrm{n}$. We note that until $\mathrm{n}=$ 32 the 0 -cuts of $D(x)$, take only negative values, that is to say $C_{A}>C_{B}$ so the best alternative is $\mathrm{B}$. From $\mathrm{n}=33$ to $\mathrm{n}=36$ the left tails negative and the right tail positive, so we maybe have a better alternative we maybe not because the difference can be zero for a specific membership grade $(\mathrm{a}=0.02)$. From $\mathrm{n}=37$ and then the 0 -cuts of $D(x)$ are positive that is to say $C_{A}<C_{B}$ so the best alternative is A. We can confirm these results if we zoom in figure (1). So, let us see in figure (4): Until the intersection of ${ }^{0} C_{A r}$ with ${ }^{0} C_{B l}$ we have that $C_{A}>C_{B}$. From this point, until the intersection of ${ }^{0} C_{A l}$ with ${ }^{0} C_{B r}$ we maybe have a better alternative we maybe not, because the difference can be zero. From this point and then, $C_{A}<C_{B}$. In figures (2) and (3) (example for $\mathrm{n}=35$ ), we present the fuzzy estimators for the costs and difference respectively. In figure 2 the $\mathrm{x}$ axis represents the cost and the $\mathrm{y}$ axis represents the membership grade on $[0,1]$ of the membership function of the fuzzy estimator for cost. In figure 3 the $\mathrm{x}$ axis represents the difference of costs of the two alternatives and the $y$ axis represents the membership grade on $[0,1]$ of the membership function of the fuzzy estimator for the difference $\mathrm{D}(\mathrm{x})$. 
In our paper we do not use probability theory but fuzzy sets theory. The table we developed (Table 1) presents the difference between costs of the two alternatives as a fuzzy number and in particular as a fuzzy estimator. Our target is not to talk about the probabilities of alternatives as Finch and Gavirneni [9] do. For each production volume (n) we provide a fuzzy estimator for the difference of costs of the alternatives. This fuzzy number is defined on $[0,1]$. Thus we can derive for every membership grade on $[0,1]$ (and not probability) which is the sign of the difference $\mathrm{D}(\mathrm{x})$ and consequently which alternative is most preferable. For example we can say that for production volume $n=35$, with membership grade 0.96 , the difference $\mathrm{D}(\mathrm{x}) \in[284.07,315.93]$. Thus it is easy to understand that since $\mathrm{D}(\mathrm{x})>0$ the best alternative is $\mathrm{B}$. Reversely we can search the membership grade for certain $(\mathrm{n})$ and $\mathrm{D}(\mathrm{x})$. For example, for production volume $\mathrm{n}=35$ the difference $\mathrm{D}(\mathrm{x})=199.4$ with membership grade 0.75 . The same process we can follow for all production volumes, for all membership grades $[0,1]$. In that we way we consider that we have managed to provide a more detailed analysis. Furthermore we believe that this method is a completely new approach, which gives us the opportunity to develop o a completely new "philosophy" in cost analysis. It is a fact that this method is more complicated mathematically. That is why we developed simple software which can realize these operations comfortably and easy.

Figure 1: Curves of ${ }^{a} C_{A},{ }^{a} C_{B}$.

Figure 2: Fuzzy Estimators of $C_{A}(x), C_{B}(x)$ for $n=35$.

Figure 3: Fuzzy Estimators of $D(x)$ for $n=35$.

Figure 4: Zoom in curves of ${ }^{a} C_{A},{ }^{a} C_{B}$.

Table 1: Fuzzy estimators of $D(x)$, for different production volumes.

In Finch, Gavirneni (2006) the authors developed a formula which shows the probabilities for which alternatives $A$ and $B$ are low cost for any value of $n$. In this paper, we provide a fuzzy estimator for $D(x)$ using formula (5.16) (difference of costs of the alternatives) Thus if we want to talk simple we can say that with our method we derive a fuzzy number for the difference between the costs of the alternatives. Reversely, we can also search which is the membership grade for certain production volume (n) and certain $\mathrm{D}(\mathrm{x})$. Furthermore we can do the same thing for the costs by using the fuzzy estimators for them by (5.5) and (5.6). As we can see, we managed to provide a more detailed analysis as concerning the choice of the best alternative.

\section{CVP analysis under uncertainty}

The fact that the CVP analysis is based on some limiting assumptions, we have mentioned above, decrease its usefulness. Here we try to remove some of these assumptions so that the breakeven point analysis can be used in cases where the information is limited. According to quality and the quantity of the information given as concerning a specific financial condition we can discriminate three kinds of uncertainty: ignorance, economic indeterminacy, risk. The case of ignorance is when we lack of information. Economic indeterminacy is the case that the decision of a company or a manager depends on the actions of other companies or managers. Risk is the variance of the profit that the companies can realize [Holmen (1990), Shubic (1954)].

Let us consider a company which wants to choose between products A and B. Each of them can be produced in the currents plants and demands an increase in the fixed cost of the company of 20000USD. The contribution margin is 4USD. According to this data the breakeven point for both products is 5000 units. So the company cannot decide which of these two products to choose. In other words the traditional 
breakeven analysis gives the company the capability to compute the breakeven point of each product, but it cannot discriminate between the two products. This weakness is due to the fact that the traditional breakeven analysis assumes cost (fixed and variable) price and volume as certain variables. Here we use the fuzzy estimators (here we use the a-cuts in order to realize the operations of fuzzy numbers) in order to express the uncertainty of these parameters. So let us consider:

$$
\begin{aligned}
& { }^{a} E(F)=\left[f-z_{g(a)} \frac{\sigma_{f}}{\sqrt{n_{f}}}, f+z_{g(a)} \frac{\sigma_{f}}{\sqrt{n_{f}}}\right] \\
& { }^{a} E(P)=\left[p-z_{g(a)} \frac{\sigma_{p}}{\sqrt{n_{p}}}, p+z_{g(a)} \frac{\sigma_{p}}{\sqrt{n_{p}}}\right] \\
& { }^{a} E(V)=\left[v-z_{g(a)} \frac{\sigma_{v}}{\sqrt{n_{v}}}, v+z_{g(a)} \frac{\sigma_{v}}{\sqrt{n_{v}}}\right] \\
& { }^{a} E(Q)=\left[q-z_{g(a)} \frac{\sigma_{q}}{\sqrt{n_{q}}}, q+z_{g(a)} \frac{\sigma_{q}}{\sqrt{n_{q}}}\right]
\end{aligned}
$$

Thus the profits can be described by the following formula [Yunker and Yunker (2003)]:

$$
\text { profits }=Q(P-V)-F
$$

Q: production volume, P: price, V: variable costs, F: fixed cost

By considering them as random variables we take the expected values:

$$
E(\text { profits })=E(Q)[E(P)-E(V)]-E(F)
$$

Then we make use of fuzzy estimators:

$$
\begin{gathered}
{ }^{a} E(\text { profits })={ }^{a} E(Q)\left[{ }^{a} E(P)-{ }^{a} E(V)\right]-{ }^{a} E(F) \leftrightarrow \\
{ }^{a} E(\text { profits })_{l}=\left(q-z_{g(a)} \frac{\sigma_{q}}{\sqrt{n_{q}}}\right)\left(p-z_{g(a)} \frac{\sigma_{p}}{\sqrt{n_{p}}}-v-z_{g(a)} \frac{\sigma_{v}}{\sqrt{n_{v}}}\right)-f-z_{g(a)} \frac{\sigma_{f}}{\sqrt{n_{f}}} \\
{ }^{a} E(\text { profits })_{r}=\left(q+z_{g(a)} \frac{\sigma_{q}}{\sqrt{n_{q}}}\right)\left(p+z_{g(a)} \frac{\sigma_{p}}{\sqrt{n_{p}}}-v+z_{g(a)} \frac{\sigma_{v}}{\sqrt{n_{v}}}\right)-f+z_{g(a)} \frac{\sigma_{f}}{\sqrt{n_{f}}}
\end{gathered}
$$

The risk can be expressed with the standard deviation of the profits:

$$
\sigma=\sqrt{\sigma_{Q}^{2}\left(\sigma_{P}^{2}+\sigma_{V}^{2}\right)+E^{2}(Q)\left(\sigma_{P}^{2}+\sigma_{V}^{2}\right)+[E(P)-E(V)]^{2} \sigma_{Q}^{2}+\sigma_{F}^{2}}
$$

Then we make use of fuzzy estimators and by realizing the appropriate operations we derive: 
${ }^{a} S D(\text { risk })_{l}=$

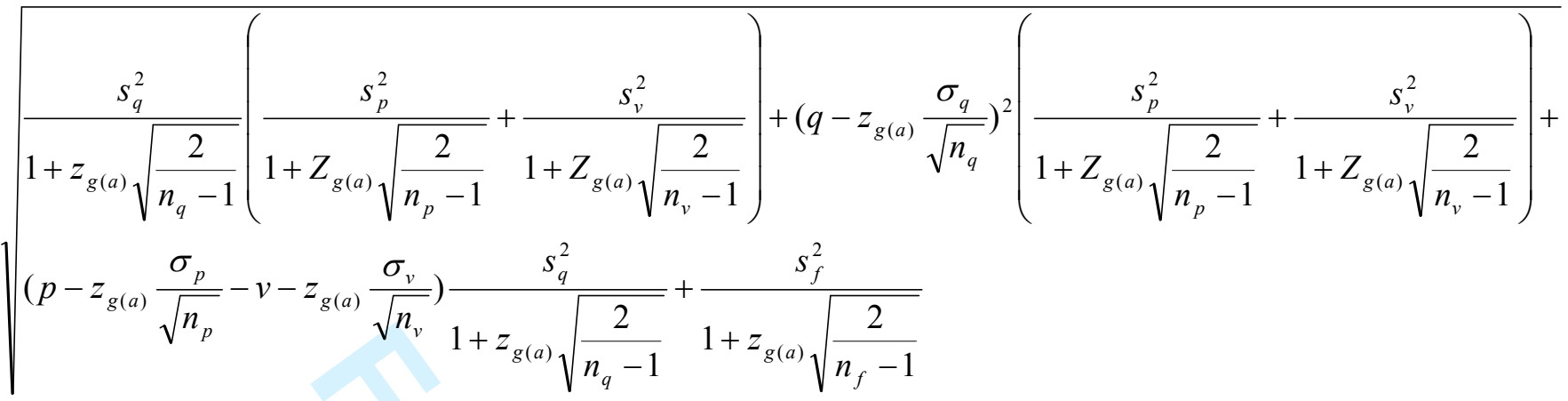

${ }^{a} S D(\text { risk })_{r}=$

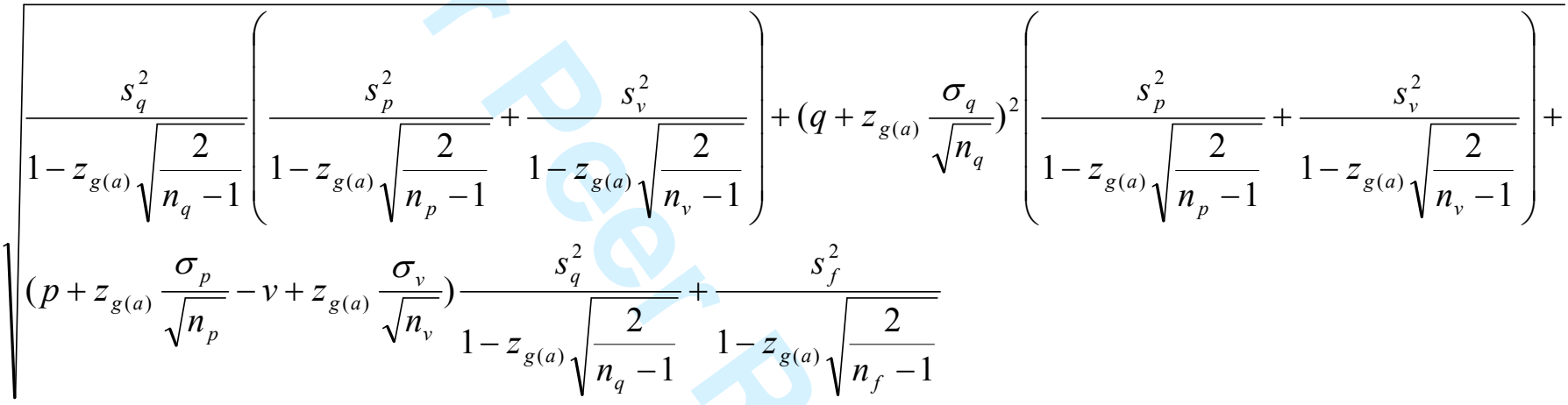

(6.10)

Numerical Example: We now assume that the all the factors of the breakeven point analysis are random variables (fixed cost, variable cost per unit, price per unit). We do not know the distribution function of these random variables but we make use of fuzzy estimators thus, we do not need to. So let us consider the next data: Product A: The average fixed cost is 20000USD which results from a sample of 36 observations with standard deviation to be 2000, the price per unit is 20USD and results from a sample of 36 observations with standard deviation to be 2, the variable cost per unit is 16USD and results from a sample of 36 observations with standard deviation to be 1.5, the production volume is 7000 and results from a sample of 36 observations with standard deviation to be 500. Product B: The average fixed cost is 20000USD which results from a sample of 36 observations with standard deviation to be 1500 , the price per unit is 20USD and results from a sample of 36 observations with standard deviation to be 2.5 , the variable cost per unit is 16USD and results from a sample of 36 observations with standard deviation to be 1 , the production volume is 7000 and results from a sample of 36 observations with standard deviation to be 500 .

Solution: The 0 -cut of profits for the product $A$ is ${ }^{0} E$ (profits $)_{A}=[-3911.45,20556.37]$ and for ${ }^{0} E$ (profits $)_{B}=[-3696.82,20341.74]$. As concerning the 1 -cut it is easy to see that ${ }^{1} E$ ( profits $)_{A}={ }^{1} E(\text { profits })_{B}=8000$. The 0 -cut of risk for the product $\mathrm{A}$ is ${ }^{0} S D_{A}=[2016.38,6387.37]$ and for $^{0} S D_{B}=[1755.74,6180.87]$. As concerning the 1 -cut it is easy to see that ${ }^{1} S D_{A}=3099.4$ and ${ }^{1} S D_{B}=2848.38$. Next we depict the fuzzy estimators for profit and risk for each product.

Figures 5, 6: Fuzzy Estimators of profit (up) and risk (down) for product A. 
Figures 7, 8: Fuzzy Estimators of profit (up) and risk (down) for product B.

For the figures 5, 7 the $\mathrm{x}$ axis represents the profit and the $\mathrm{y}$ axis the membership grade. For figures 6,8 the $\mathrm{x}$ axis represents the risk (measured by standard deviation) and the $\mathrm{y}$ axis the membership grade. Thus for each membership grade the company can decide for the choice of the combination of risk and profit comparing these two products.

\section{Fuzzy Estimators for the Breakeven Point in Production Volume}

According to this methodology we can consider that the profits are zero. Thus we can derive the fuzzy breakeven point. The break even point in production volume is given by the equation:

$$
Q^{*}=\frac{F}{P-V}
$$

We consider total fixed cost, price per unit, and variable cost per unit as random variables. So we have the above equation under uncertainty by having the expected prices of these variables.

$$
E\left(Q^{*}\right)=\frac{E(F)}{E(P)-E(V)}
$$

Now we consider the fuzzy estimators for the expected prices of these variables.

$$
\begin{aligned}
& { }^{a} E(F)=\left[f-z_{g(a)} \frac{\sigma_{f}}{\sqrt{n_{f}}}, f+z_{g(a)} \frac{\sigma_{f}}{\sqrt{n_{f}}}\right] \\
& { }^{a} E(P)=\left[p-z_{g(a)} \frac{\sigma_{p}}{\sqrt{n_{p}}}, p+z_{g(a)} \frac{\sigma_{p}}{\sqrt{n_{p}}}\right] \\
& { }^{a} E(V)=\left[v-z_{g(a)} \frac{\sigma_{v}}{\sqrt{n_{v}}}, v+z_{g(a)} \frac{\sigma_{v}}{\sqrt{n_{v}}}\right]
\end{aligned}
$$

Thus we have:

$$
{ }^{a} E\left(Q^{*}\right)=\frac{\left[f-z_{g(a)} \frac{\sigma_{f}}{\sqrt{n_{f}}}, f+z_{g(a)} \frac{\sigma_{f}}{\sqrt{n_{f}}}\right]}{\left[p-z_{g(a)} \frac{\sigma_{p}}{\sqrt{n_{p}}}-v-z_{g(a)} \frac{\sigma_{v}}{\sqrt{n_{v}}}, p+z_{g(a)} \frac{\sigma_{p}}{\sqrt{n_{p}}}-v+z_{g(a)} \frac{\sigma_{v}}{\sqrt{n_{v}}}\right]}
$$




$$
\begin{gathered}
{ }^{a} E\left(Q^{*}\right)_{l}=\frac{f-z_{g(a)} \frac{\sigma_{f}}{\sqrt{n_{f}}}}{p+z_{g(a)} \frac{\sigma_{p}}{\sqrt{n_{p}}}-v+z_{g(a)} \frac{\sigma_{v}}{\sqrt{n_{v}}}} \text { and } \\
{ }^{a} E\left(Q^{*}\right)_{r}=\frac{f+z_{g(a)} \frac{\sigma_{f}}{\sqrt{n_{f}}}}{p-z_{g(a)} \frac{\sigma_{p}}{\sqrt{n_{p}}}-v-z_{g(a)} \frac{\sigma_{v}}{\sqrt{n_{v}}}}
\end{gathered}
$$

We now need to find the fuzzy number for this a-cut.

I) Let:

$$
\begin{aligned}
& x=\frac{f-z_{g(a)} \frac{\sigma_{f}}{\sqrt{n_{f}}}}{p+z_{g(a)} \frac{\sigma_{p}}{\sqrt{n_{p}}}-v+z_{g(a)} \frac{\sigma_{v}}{\sqrt{n_{v}}}} \leftrightarrow x p+x z_{g(a)} \frac{\sigma_{p}}{\sqrt{n_{p}}}-v x+x z_{g(a)} \frac{\sigma_{v}}{\sqrt{n_{v}}}=f-z_{g(a)} \frac{\sigma_{f}}{\sqrt{n_{f}}} \leftrightarrow \\
& x p+z_{g(a)}\left(x \frac{\sigma_{p}}{\sqrt{n_{p}}}+x \frac{\sigma_{v}}{\sqrt{n_{v}}}+\frac{\sigma_{f}}{\sqrt{n_{f}}}\right)-v x=f \leftrightarrow z_{g(a)}=\frac{f+v x-x p}{x \frac{\sigma_{p}}{\sqrt{n_{p}}}+x \frac{\sigma_{v}}{\sqrt{n_{v}}}+\frac{\sigma_{f}}{\sqrt{n_{f}}}} \leftrightarrow \\
& \Phi^{-1}(1-g(a))=\frac{f+v x-x p}{x \frac{\sigma_{p}}{\sqrt{n_{p}}}+x \frac{\sigma_{v}}{\sqrt{n_{v}}}+\frac{\sigma_{f}}{\sqrt{n_{f}}}} \leftrightarrow 1-g(a)=\Phi\left(\frac{f+v x-x p}{x \frac{\sigma_{p}}{\sqrt{n_{p}}}+x \frac{\sigma_{v}}{\sqrt{n_{v}}}+\frac{\sigma_{f}}{\sqrt{n_{f}}}}\right) \leftrightarrow \\
& \left(\frac{1-\beta}{2}\right) a+\frac{\beta}{2}=1-\Phi\left(\frac{f+v x-x p}{x \frac{\sigma_{p}}{\sqrt{n_{p}}}+x \frac{\sigma_{v}}{\sqrt{n_{v}}}+\frac{\sigma_{f}}{\sqrt{n_{f}}}}\right) \leftrightarrow\left(\frac{1-\beta}{2}\right) a+\frac{\beta}{2}=\Phi\left(\frac{-f-v x+x p}{x \frac{\sigma_{p}}{\sqrt{n_{p}}}+x \frac{\sigma_{v}}{\sqrt{n_{v}}}+\frac{\sigma_{f}}{\sqrt{n_{f}}}}\right) \leftrightarrow
\end{aligned}
$$

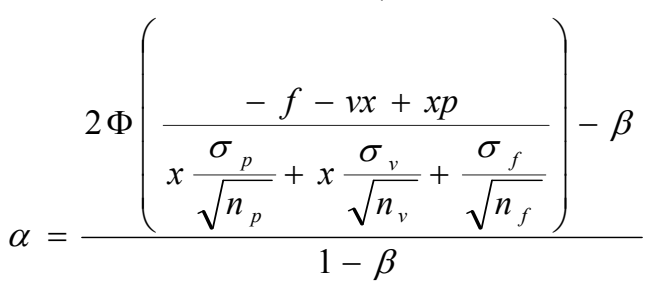

But $a \in[0,1]$ thus, 


$$
\begin{aligned}
& 0 \leq \frac{2 \Phi\left(\frac{-f-v x+x p}{x \frac{\sigma_{p}}{\sqrt{n_{p}}}+x \frac{\sigma_{v}}{\sqrt{n_{v}}}+\frac{\sigma_{f}}{\sqrt{n_{f}}}}\right)-\beta}{1-\beta} \leq 1 \leftrightarrow \beta \leq 2 \Phi\left(\frac{-f-v x+x p}{x \frac{\sigma_{p}}{\sqrt{n_{p}}}+x \frac{\sigma_{v}}{\sqrt{n_{v}}}+\frac{\sigma_{f}}{\sqrt{n_{f}}}}\right) \leq 1 \leftrightarrow \\
& \Phi^{-1}\left(\frac{\beta}{2}\right) \leq \frac{-f-v x+x p}{x \frac{\sigma_{p}}{\sqrt{n_{p}}}+x \frac{\sigma_{v}}{\sqrt{n_{v}}}+\frac{\sigma_{f}}{\sqrt{n_{f}}}} \leq 0
\end{aligned}
$$

So we have the next two inequalities:

1)

$$
\frac{-f-v x+x p}{x \frac{\sigma_{p}}{\sqrt{n_{p}}}+x \frac{\sigma_{v}}{\sqrt{n_{v}}}+\frac{\sigma_{f}}{\sqrt{n_{f}}}} \leq 0 \leftrightarrow x(p-v) \leq f \text { but } p-v>0 \text { thus } x \leq \frac{f}{p-v}
$$

2)

$$
\begin{gathered}
\Phi^{-1}\left(\frac{\beta}{2}\right) \leq \frac{-f-v x+x p}{x \frac{\sigma_{p}}{\sqrt{n_{p}}}+x \frac{\sigma_{v}}{\sqrt{n_{v}}}+\frac{\sigma_{f}}{\sqrt{n_{f}}}} \leftrightarrow p x-v x-f \geq \Phi^{-1}\left(\frac{\beta}{2}\right) \frac{\sigma_{p}}{\sqrt{n_{p}}} x+\Phi^{-1}\left(\frac{\beta}{2}\right) \frac{\sigma_{v}}{\sqrt{n_{v}}} x+\Phi^{-1}\left(\frac{\beta}{2}\right) \frac{\sigma_{f}}{\sqrt{n_{f}}} \leftrightarrow \\
x\left[p-v-\Phi^{-1}\left(\frac{\beta}{2}\right)\left(\frac{\sigma_{p}}{\sqrt{n_{p}}}+\frac{\sigma_{v}}{\sqrt{n_{v}}}\right)\right] \geq \Phi^{-1}\left(\frac{\beta}{2}\right) \frac{\sigma_{f}}{\sqrt{n_{f}}} x+f \leftrightarrow x \geq \frac{\Phi^{-1}\left(\frac{\beta}{2}\right) \frac{\sigma_{f}}{\sqrt{n_{f}}}+f}{p-v-\Phi^{-1}\left(\frac{\beta}{2}\right)\left(\frac{\sigma_{p}}{\sqrt{n_{p}}}+\frac{\sigma_{v}}{\sqrt{n_{v}}}\right)}
\end{gathered}
$$

We can divide with $\left[p-v-\Phi^{-1}\left(\frac{\beta}{2}\right)\left(\frac{\sigma_{p}}{\sqrt{n_{p}}}+\frac{\sigma_{v}}{\sqrt{n_{v}}}\right)\right]$ without changing the inequality because $\left[p-v-\Phi^{-1}\left(\frac{\beta}{2}\right)\left(\frac{\sigma_{p}}{\sqrt{n_{p}}}+\frac{\sigma_{v}}{\sqrt{n_{v}}}\right)\right]>0$ since $p-v>0$ and $\Phi^{-1}\left(\frac{\beta}{2}\right)\left(\frac{\sigma_{p}}{\sqrt{n_{p}}}+\frac{\sigma_{v}}{\sqrt{n_{v}}}\right)<0$ for $\beta=0.01$ that we will use next. 
II) Let:

$$
\begin{aligned}
& x=\frac{f+z_{g(a)} \frac{\sigma_{f}}{\sqrt{n_{f}}}}{p-z_{g(a)} \frac{\sigma_{p}}{\sqrt{n_{p}}}-v-z_{g(a)} \frac{\sigma_{v}}{\sqrt{n_{v}}}} \leftrightarrow x p-x z_{g(a)} \frac{\sigma_{p}}{\sqrt{n_{p}}}-v x-x z_{g(a)} \frac{\sigma_{v}}{\sqrt{n_{v}}}=f+z_{g(a)} \frac{\sigma_{f}}{\sqrt{n_{f}}} \leftrightarrow \\
& x p-z_{g(a)}\left(x \frac{\sigma_{p}}{\sqrt{n_{p}}}+x \frac{\sigma_{v}}{\sqrt{n_{v}}}+\frac{\sigma_{f}}{\sqrt{n_{f}}}\right)-v x=f \leftrightarrow z_{g(a)}=\frac{-f-v x+x p}{x \frac{\sigma_{p}}{\sqrt{n_{p}}}+x \frac{\sigma_{v}}{\sqrt{n_{v}}}+\frac{\sigma_{f}}{\sqrt{n_{f}}}} \leftrightarrow \\
& \Phi^{-1}(1-g(a))=\frac{-f-v x+x p}{x \frac{\sigma_{p}}{\sqrt{n_{p}}}+x \frac{\sigma_{v}}{\sqrt{n_{v}}}+\frac{\sigma_{f}}{\sqrt{n_{f}}}} \leftrightarrow 1-g(a)=\Phi\left(\frac{-f-v x+x p}{x \frac{\sigma_{p}}{\sqrt{n_{p}}}+x \frac{\sigma_{v}}{\sqrt{n_{v}}}+\frac{\sigma_{f}}{\sqrt{n_{f}}}}\right) \leftrightarrow \\
& \left(\frac{1-\beta}{2}\right) a+\frac{\beta}{2}=1-\Phi\left(\frac{-f-v x+x p}{x \frac{\sigma_{p}}{\sqrt{n_{p}}}+x \frac{\sigma_{v}}{\sqrt{n_{v}}}+\frac{\sigma_{f}}{\sqrt{n_{f}}}}\right) \leftrightarrow\left(\frac{1-\beta}{2}\right) a+\frac{\beta}{2}=\Phi\left(\frac{f+v x-x p}{x \frac{\sigma_{p}}{\sqrt{n_{p}}}+x \frac{\sigma_{v}}{\sqrt{n_{v}}}+\frac{\sigma_{f}}{\sqrt{n_{f}}}}\right) \leftrightarrow \\
& \alpha=\frac{2 \Phi\left(\frac{f+v x-x p}{x \frac{\sigma_{p}}{\sqrt{n_{p}}}+x \frac{\sigma_{v}}{\sqrt{n_{v}}}+\frac{\sigma_{f}}{\sqrt{n_{f}}}}\right)-\beta}{1-\beta}
\end{aligned}
$$

But $a \in[0,1]$ thus,

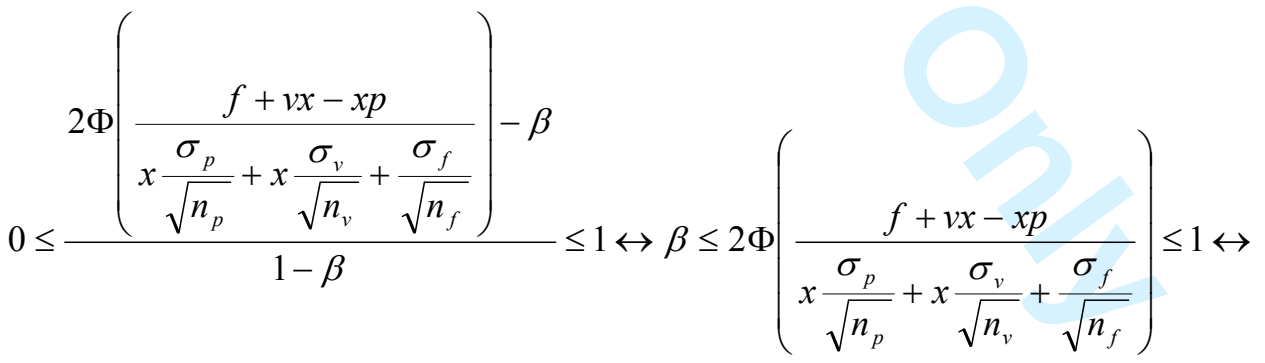

$$
\begin{aligned}
& \Phi^{-1}\left(\frac{\beta}{2}\right) \leq \frac{f+v x-x p}{x \frac{\sigma_{p}}{\sqrt{n_{p}}}+x \frac{\sigma_{v}}{\sqrt{n_{v}}}+\frac{\sigma_{f}}{\sqrt{n_{f}}}} \leq 0
\end{aligned}
$$

So we have the next two inequalities: 
1)

$$
\frac{f+v x-x p}{x \frac{\sigma_{p}}{\sqrt{n_{p}}}+x \frac{\sigma_{v}}{\sqrt{n_{v}}}+\frac{\sigma_{f}}{\sqrt{n_{f}}}}<0 \leftrightarrow x(v-p) \leq f \text { but } v-p<0 \text { thus } x>\frac{f}{p-v}
$$

2)

$$
\begin{gathered}
\Phi^{-1}\left(\frac{\beta}{2}\right) \leq \frac{f+v x-x p}{x \frac{\sigma_{p}}{\sqrt{n_{p}}}+x \frac{\sigma_{v}}{\sqrt{n_{v}}}+\frac{\sigma_{f}}{\sqrt{n_{f}}}} \leftrightarrow-p x+v x+f \geq \Phi^{-1}\left(\frac{\beta}{2}\right) \frac{\sigma_{p}}{\sqrt{n_{p}}} x+\Phi^{-1}\left(\frac{\beta}{2}\right) \frac{\sigma_{v}}{\sqrt{n_{v}}} x+\Phi^{-1}\left(\frac{\beta}{2}\right) \frac{\sigma_{f}}{\sqrt{n_{f}}} \leftrightarrow \\
x\left[p-v+\Phi^{-1}\left(\frac{\beta}{2}\right)\left(\frac{\sigma_{p}}{\sqrt{n_{p}}}+\frac{\sigma_{v}}{\sqrt{n_{v}}}\right)\right] \leq-\Phi^{-1}\left(\frac{\beta}{2}\right) \frac{\sigma_{f}}{\sqrt{n_{f}}}+f \leftrightarrow x \leq \frac{-\Phi^{-1}\left(\frac{\beta}{2}\right) \frac{\sigma_{f}}{\sqrt{n_{f}}}+f}{p-v-\Phi^{-1}\left(\frac{\beta}{2}\right)\left(\frac{\sigma_{p}}{\sqrt{n_{p}}}+\frac{\sigma_{v}}{\sqrt{n_{v}}}\right)}
\end{gathered}
$$

We can divide with $\left[p-v-\Phi^{-1}\left(\frac{\beta}{2}\right)\left(\frac{\sigma_{p}}{\sqrt{n_{p}}}+\frac{\sigma_{v}}{\sqrt{n_{v}}}\right)\right]$ without changing the inequality because $\left[p-v-\Phi^{-1}\left(\frac{\beta}{2}\right)\left(\frac{\sigma_{p}}{\sqrt{n_{p}}}+\frac{\sigma_{v}}{\sqrt{n_{v}}}\right)\right]>0$ since $p-v>0$ and for $\Phi^{-1}\left(\frac{\beta}{2}\right)\left(\frac{\sigma_{p}}{\sqrt{n_{p}}}+\frac{\sigma_{v}}{\sqrt{n_{v}}}\right)<0 \quad \beta=0.01$ that we will use next.

So we derived that the fuzzy break even point in units of product is:

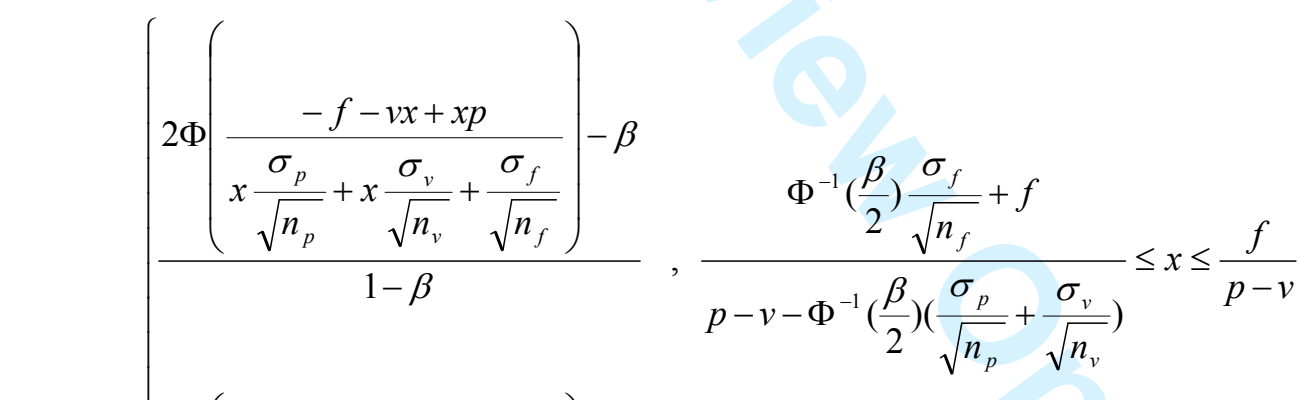

$$
\begin{aligned}
& \bar{Q}^{*}(x)=\left\{\begin{array}{l}
2 \Phi\left(\frac{f+v x-x p}{x \frac{\sigma_{p}}{\sqrt{n_{p}}}+x \frac{\sigma_{v}}{\sqrt{n_{v}}}+\frac{\sigma_{f}}{\sqrt{n_{f}}}}\right)-\beta \\
1-\beta
\end{array}, \frac{f}{p-v}<x \leq \frac{-\Phi^{-1}\left(\frac{\beta}{2}\right) \frac{\sigma_{f}}{\sqrt{n_{f}}}+f}{p-v+\Phi^{-1}\left(\frac{\beta}{2}\right)\left(\frac{\sigma_{p}}{\sqrt{n_{p}}}+\frac{\sigma_{v}}{\sqrt{n_{v}}}\right)}\right. \\
& 0 \text { otherwise }
\end{aligned}
$$


Numerical Example: Let us consider the next data: the average fixed cost is 48000USD which results from a sample of 36 observations with standard deviation to be 500. The variable cost is 30000USD and results from a sample of 36 observations with standard deviation to be 420 . The average price per unit is 1.5USD with standard deviation to be 0.2 . The average variable cost per unit is 1.1USD with the standard deviation to be 0.2 .

Solution: By replacing in (7.18) we take the fuzzy estimator for the mean value of the breakeven point. Next we depict this fuzzy estimator. The 0 -cut of $Q^{*}(x)$ is ${ }^{0} Q^{*}=[83584.11,211193.49]$. As concerning the 1 -cut it is easy to $\sec ^{1} Q^{*}(x)==120000$. We can also write it as a fuzzy number $Q^{*}(x)=(83584.11,120000,211193.49)$. The $\mathrm{x}$ axis represents the values of that the breakeven point takes and the $\mathrm{y}$ axis represents the membership grades.

Figure 9: Fuzzy Estimators of $Q^{*}(x)$.

We estimated the fuzzy $Q^{*}$. If we consider the a-cut as a risk level, then the company based on this method can find the "position" of the breakeven point for certain levels of risk on $[0,1]$. That means that the company can make decisions according to the level of risk the decision maker takes, knowing that the breakeven point exists in this fuzzy number with a certain membership grade each time.

\section{Summary}

In this paper we presented an alternative model which expresses the uncertainty existing in CVP analysis. We used the method of non-asymptotic fuzzy estimators thus we did not need to know the distribution function of the random variable. The analysis realized via this method is more detailed than the existing probabilistic methods. Furthermore we think that we have managed to contribute in decision making of a company. That is to say we applied fuzzy estimators in a well known method (based on profit and risk) which can help a company decide which product to produce and also in the breakeven point analysis under uncertainty. In other words we applied a new methodology in traditional breakeven analysis in order to contribute in this section of research in conditions of uncertainty.

\section{References}

Asiedu, Y. and Besant, R.W. Gu, P., 2000. Simulation-based cost estimation under economic uncertainty using kernel estimator. Int. J. Prod. Res., 38, 2023-2035.

Badr, I. and Loudeback, J., 1979. Optimizing and satisfying in stochastic cost-volume-profit Analysis. Dec. Sci., 10, 205-217.

Chan, Lilian, Y., 1990. Incremental cost-volume-profit analysis. Journal of Accounting Education, 8 (2), 253-261.

Chrysafis, K. A. and Papadopoulos, B. K., 2008. On theoretical pricing of options with fuzzy estimators. Journal of Computational and Applied Mathematics, accepted manuscript.

Chung, K.H., 1993. Cost-volume-profit analysis under uncertainty when the firm has production flexibility. J. Bus. Fin. Account., 20, 583-592.

Clarke, P., 1986. Bring uncertainty into the CVP analysis. Accountancy, 98, 105-107. 
Dickinson, J.P., 1974. Cost-volume-profit analysis under uncertainty. J. Account. Res., 12, $182-187$.

Finch, B.J. and Luebbe, R.L., 1995. The impact of learning rate and constraints on system performance. Int. J. Prod. Res., 33, 631-642.

Finch, B. and Gavirneni, S., 2006. Confidence intervals for optimal selection among alternatives with stochastic variable costs. Inter. J. of Prod. Research, 44 (20), 4329-4342.

González, Luis, 2001. Multiproduct CVP analysis based on contribution rules, International Journal of Production Economics, 73 ((3), 273-284.

Jaedecke, R.K. and Robicheck, A.A., 1964. Cost-volume-profit analysis under conditions of Uncertainty. Account. Rev., 39, 917-926.

Holmen, Jayand and Knutson, Dennis and Shanholtzer, Dennis, 1990. A cash flow cost-volume-profit model, Journal of Accounting Education. 8 (2), 263-269.

Klir G. J. and Yuan B., 1995. Fuzzy Sets and Fuzzy Logic: Theory and Applications. Prentice Hall, Englewood Cliffs, New Jersey.

Lin, Z. and Chang, D., 2002. Cost-tolerance analysis model based on a neural networks method. Int. J. Prod. Res., 40, 1429-1452.

H. T. Nguyen, 1978. A Note on the Extension Principle for Fuzzy Sets. Journal of Mathematical Analysis and Applications, 64, 369-380.

Norland Jr and R.E., 1980. Refinements in the Ismail-Loucerback Stochastic CVP Model. Dec. Sci., 11, 562-572.

Papadopoulos B. K. and Sfiris D. Non-Asymptotic Fuzzy Estimators based on Confidence Intervals, Submitted for publication

Ramarathnam, Ravichandran, 1993. A decision support system for stochastic cost-volume-profit analysis. Decision Support Systems, 10 ( 4), 379-399

Sheu, C. and Krajewski, L.J., 1993. A decision model for corrective maintenance management. Int. J. Prod. Res., 32, 1365-1382.

Shih, W., 1979. A general decision model for cost-volume-profit analysis under uncertainty. Account. Rev., 54, 687-706.

Shubic, M., , 1954, Risk, Information, Ignorance and Indeterminacy. Quarterly Journal of Economic, 68 (4), 629-640.

Smunt, T.L., 1999. Log-linear and non-log-linear learning curve models for production research and cost estimation. Int. J. Prod. Res., 37, 3901-3911.

Yunker, A. James andYunker, J. Penelope, 2003. Stochastic CVP analysis as a gateway to decisionmaking under uncertainty, Journal of Accounting Education, 21 (4), 339-365.

Yunker, A. James and Yunker, J. Penelope, 1982, Cost-volume-profit analysis under uncertainty: An integration of economic and accounting concepts, Journal of Economics and Business, Volume 34, Issue 1, 21-37.

Yunker, A. James and Yunker, J. Penelope, 2003, Stochastic CVP analysis as a gateway to decisionmaking under uncertainty. J. Account. Education, 21, 339-365. 


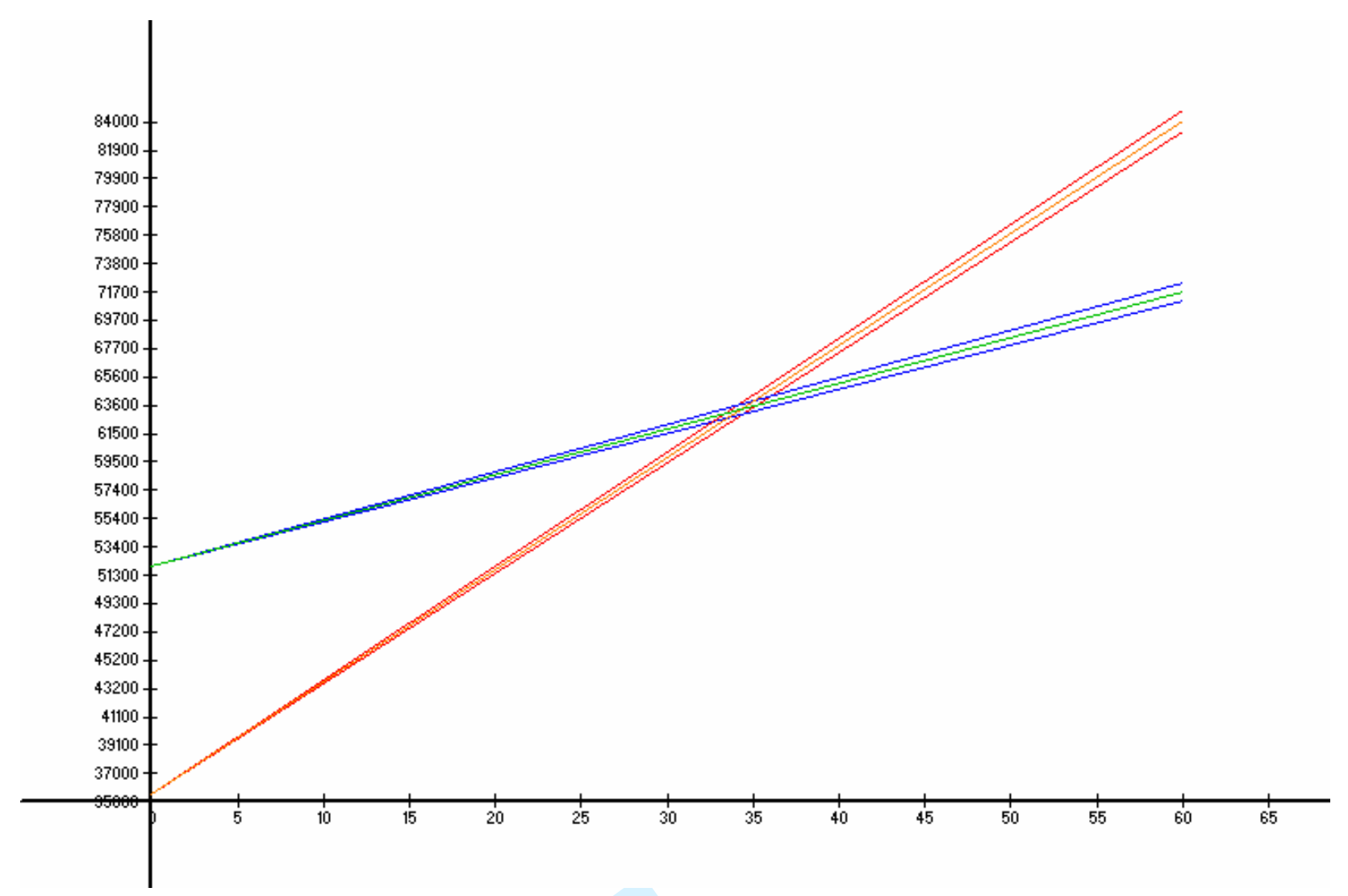

Figure 1.

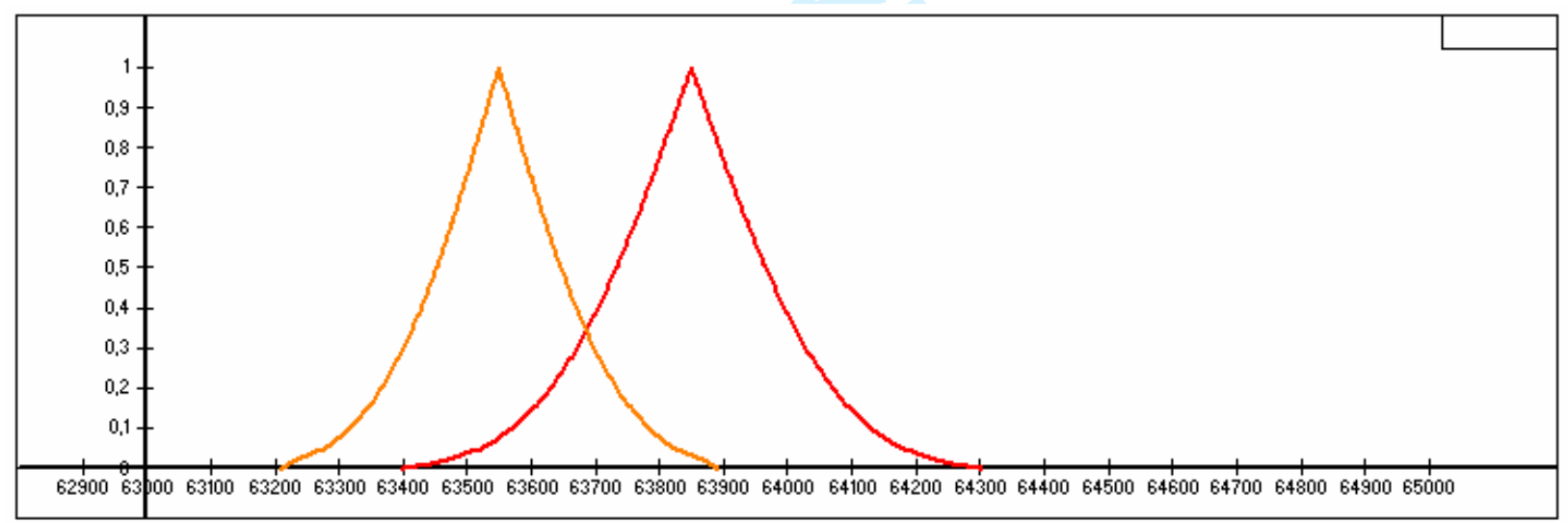

Figure 2. 


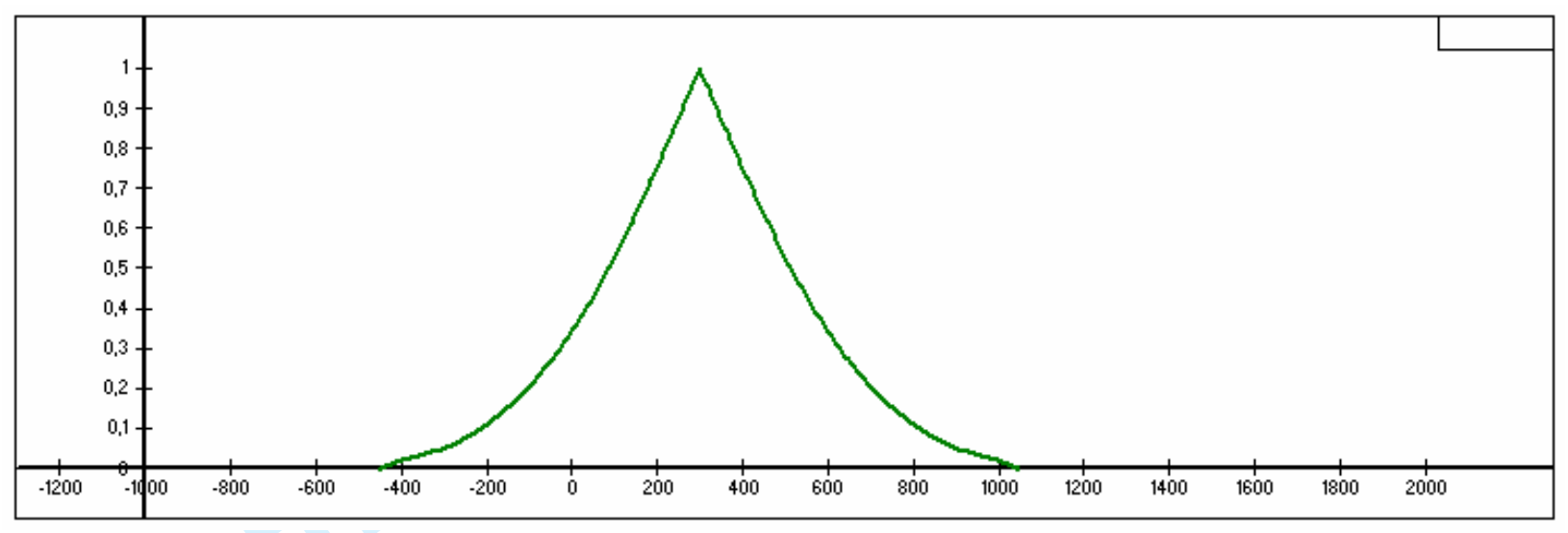

Figure 3.

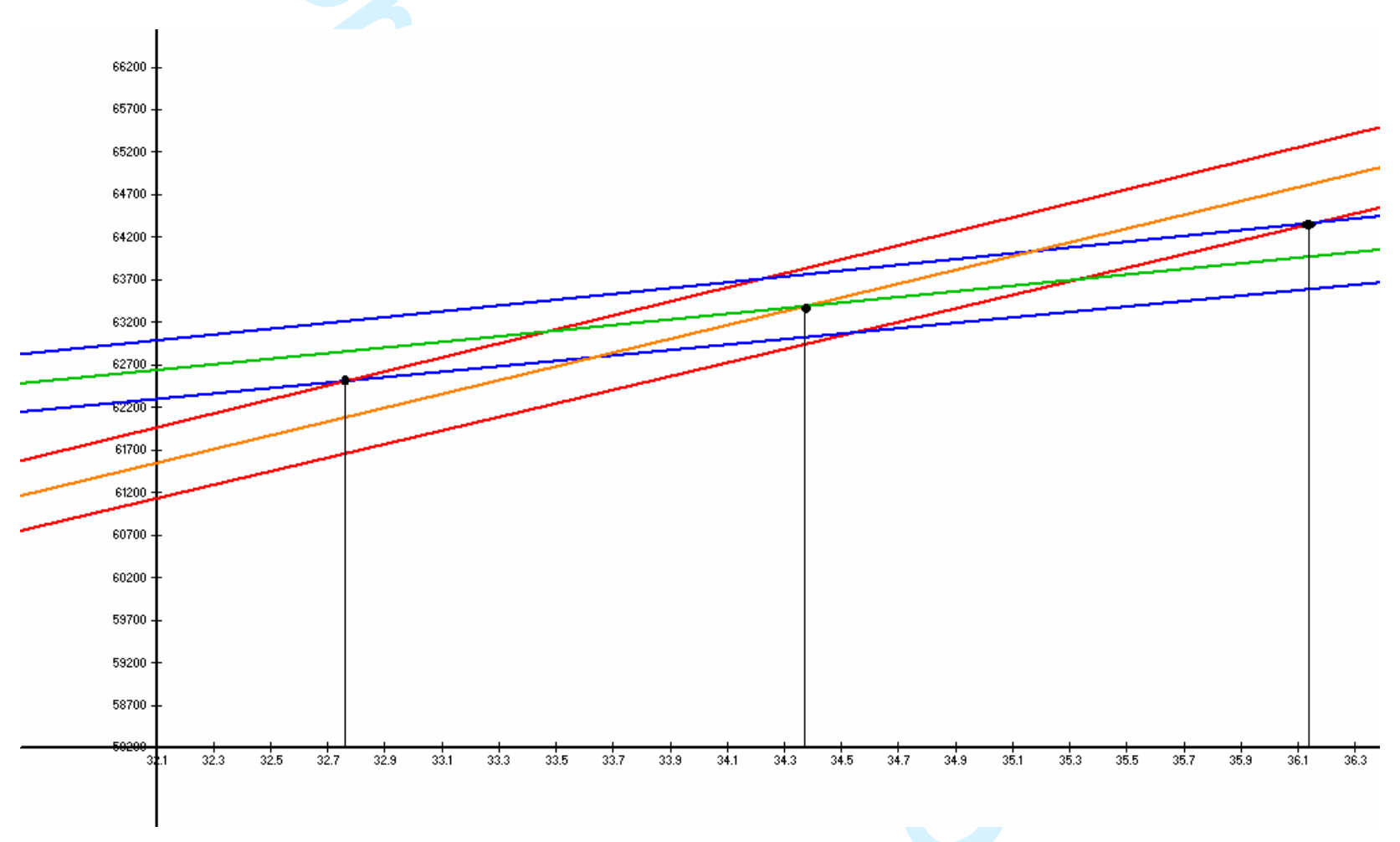

Figure 4. 

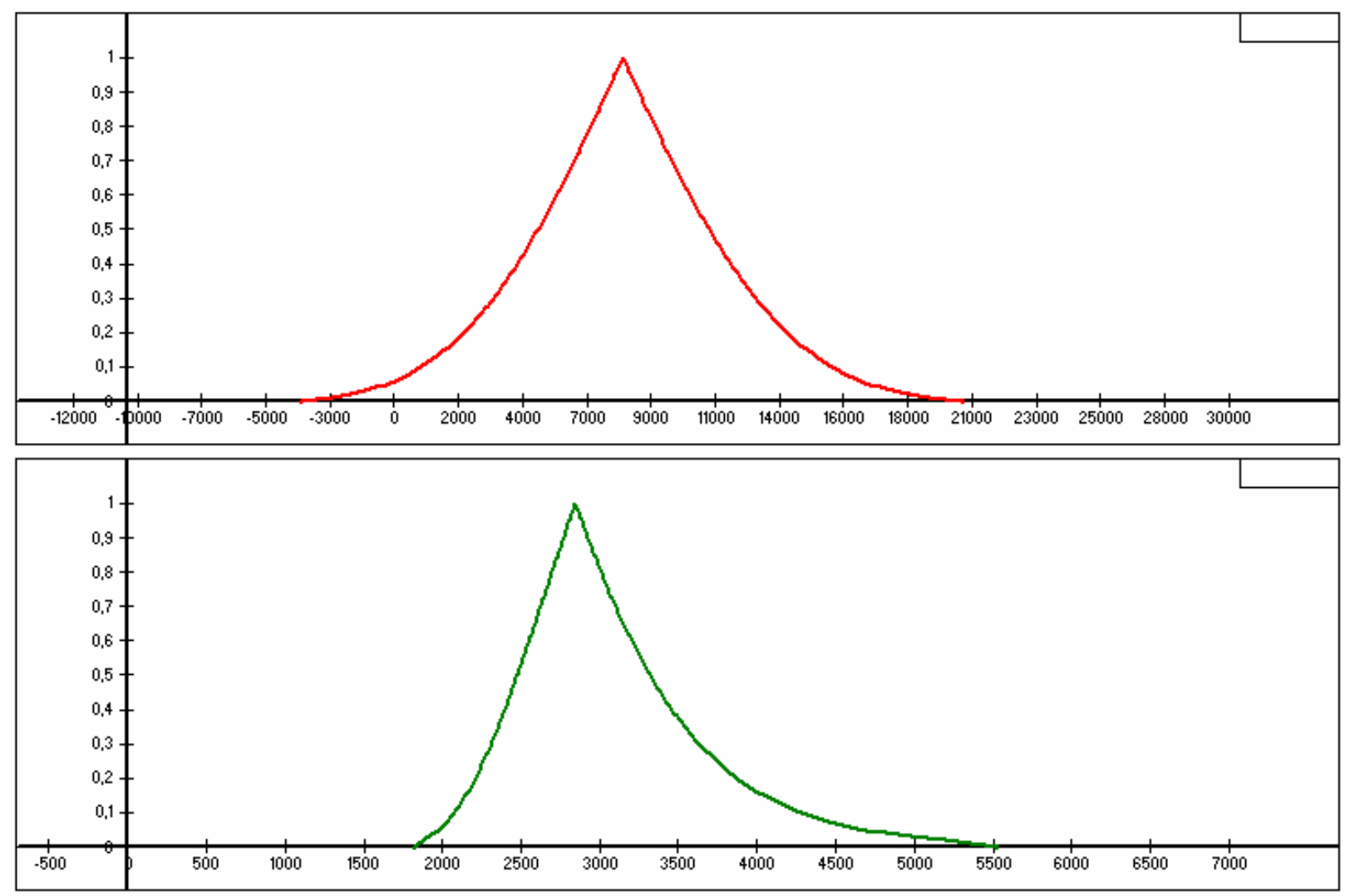

Figures 5,6. 

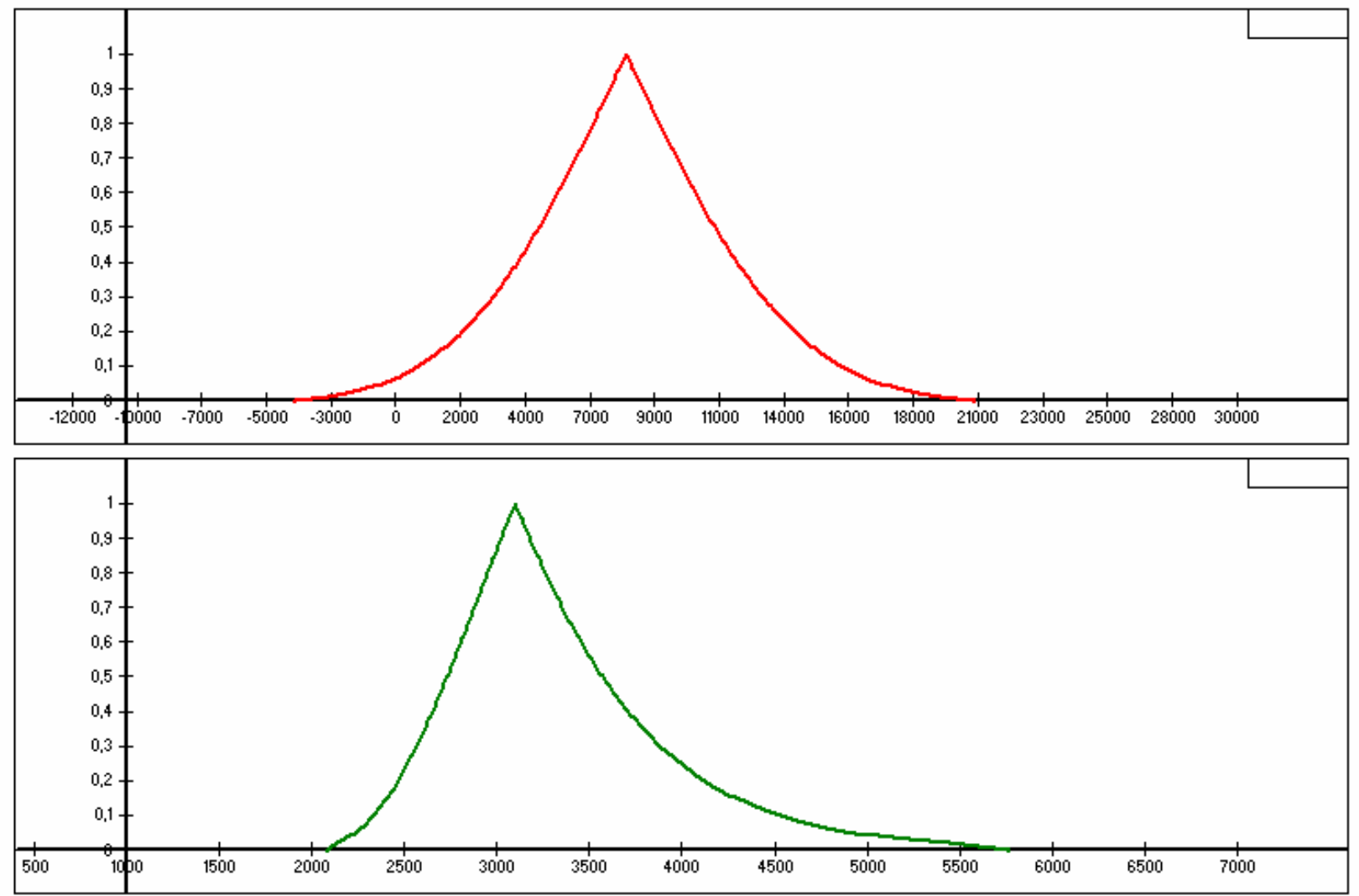

Figures 7,8. 


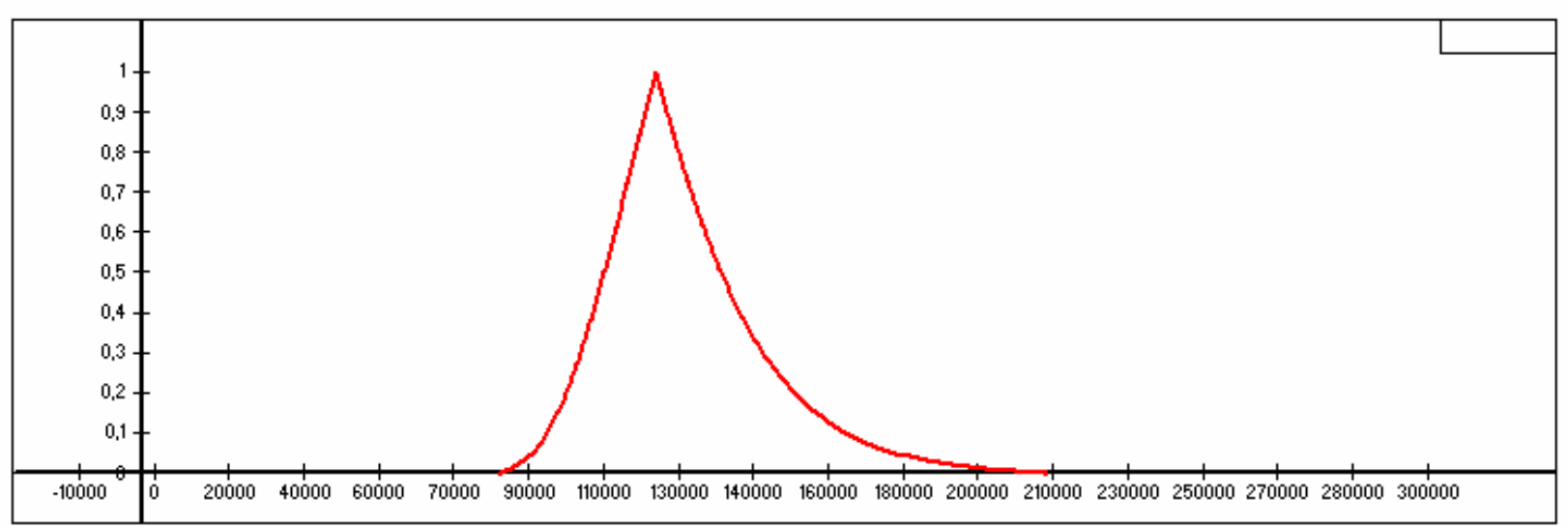

Figure 9. 


\begin{tabular}{|c|c|c|c|c|}
\hline $\mathrm{n}$ & memebership grade & \multicolumn{3}{|c|}{ difference $D(n)=x$} \\
\hline 25 & 0 & -5090.23 & 4500 & -3909.77 \\
\hline 26 & 0 & -4633.84 & & -3406.16 \\
\hline & 1 & & -4020 & \\
\hline 27 & $\begin{array}{l}0 \\
1\end{array}$ & -4177.45 & -3540 & -2902.55 \\
\hline 28 & $\begin{array}{l}0 \\
1\end{array}$ & -3271.06 & -3060 & -2398.94 \\
\hline 29 & 0 & -3264.67 & 2580 & -1895.33 \\
\hline 30 & 0 & -2808.28 & & -1391.72 \\
\hline 31 & 0 & -2351.89 & -2100 & -888.11 \\
\hline 32 & 0 & -1895.5 & -1020 & -384.5 \\
\hline 33 & $\begin{array}{l}1 \\
0 \\
1\end{array}$ & -1439.11 & -1140 & 119.11 \\
\hline 34 & $\begin{array}{l}1 \\
0 \\
1\end{array}$ & -982.72 & -180 & 622.72 \\
\hline 35 & $\begin{array}{l}0 \\
1\end{array}$ & -526.33 & 300 & 1126.33 \\
\hline 36 & $\begin{array}{l}0 \\
1\end{array}$ & -69.93 & 780 & 1629.93 \\
\hline 37 & $\begin{array}{l}0 \\
1\end{array}$ & 386.46 & 1260 & 2133.54 \\
\hline 38 & $\begin{array}{l}0 \\
1\end{array}$ & 842.85 & 1740 & 2637.15 \\
\hline 39 & $\begin{array}{l}0 \\
1\end{array}$ & 1299.24 & 2220 & 3140.76 \\
\hline 40 & $\stackrel{0}{1}$ & 1753.63 & 2700 & 3644.37 \\
\hline 41 & $\begin{array}{l}0 \\
1\end{array}$ & 2212.02 & 3180 & 4147.98 \\
\hline 42 & $\begin{array}{l}0 \\
1\end{array}$ & 2668.41 & 3660 & 4651.59 \\
\hline 43 & $\begin{array}{l}0 \\
1\end{array}$ & 3124.8 & 4140 & 5155.2 \\
\hline 44 & 0 & 3581.19 & 4620 & 5658.81 \\
\hline 45 & $\begin{array}{l}0 \\
1\end{array}$ & 4037.58 & 5100 & 6162.42 \\
\hline 46 & $\begin{array}{l}0 \\
1\end{array}$ & 4493.97 & 5580 & 6666.03 \\
\hline 47 & $\begin{array}{l}0 \\
1\end{array}$ & 4950.36 & 6060 & 7169.64 \\
\hline 48 & 0 & 5406.75 & 6540 & 7673.25 \\
\hline 49 & $\begin{array}{l}0 \\
1\end{array}$ & 5863.14 & 7020 & 8176.86 \\
\hline 50 & $\begin{array}{l}0 \\
1\end{array}$ & 6319.53 & 7500 & 8680.47 \\
\hline 51 & $\begin{array}{l}0 \\
1\end{array}$ & 6775.93 & 7980 & 9184.07 \\
\hline 52 & $\begin{array}{l}0 \\
1\end{array}$ & 7232.32 & 8640 & 9687.68 \\
\hline 53 & $\begin{array}{l}0 \\
1\end{array}$ & 7688.71 & 8940 & 10191.29 \\
\hline
\end{tabular}

Table 1. 


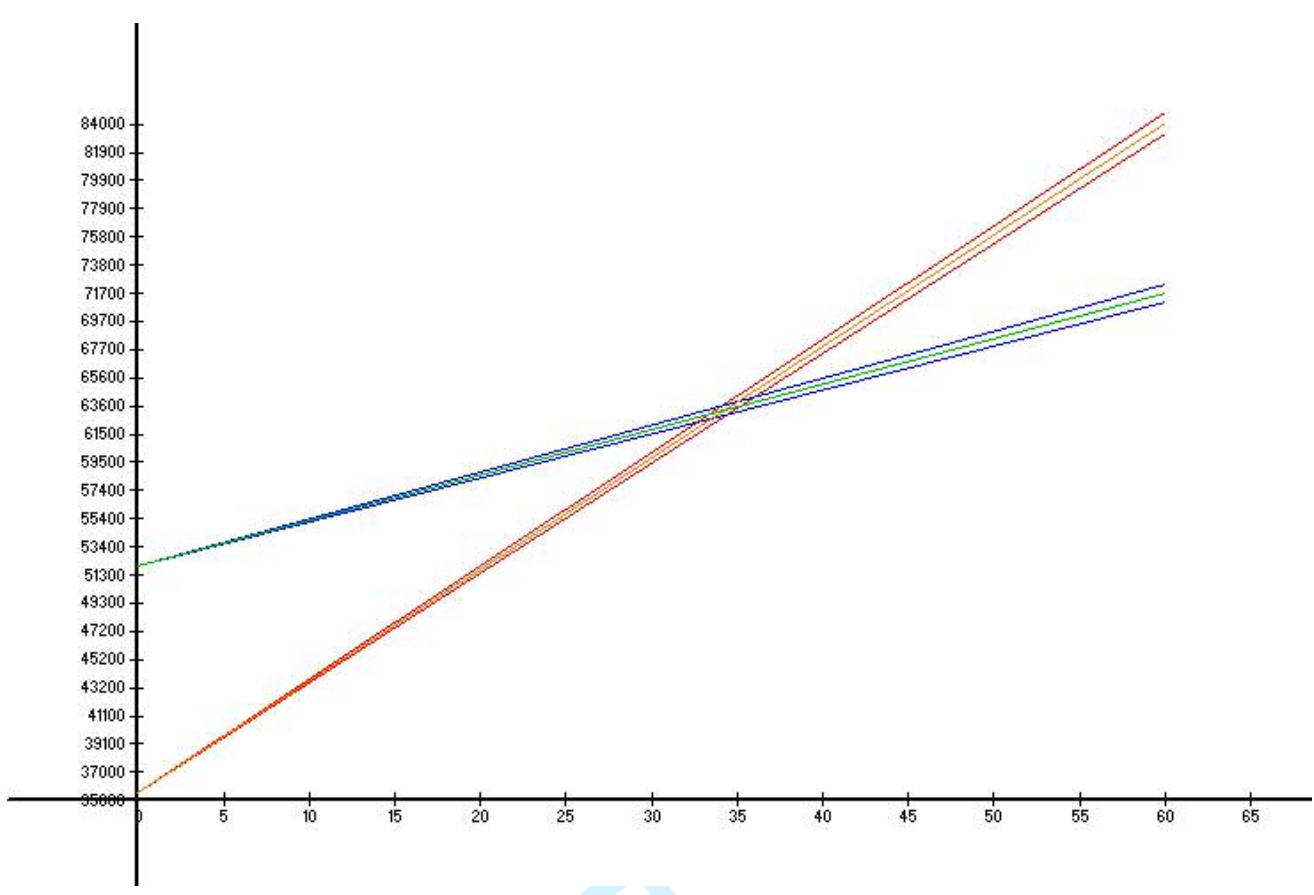

http://mc.manuscriptcentral.com/tprs Email: ijpr@lboro.ac.uk 


\section{Page 29 of 35}

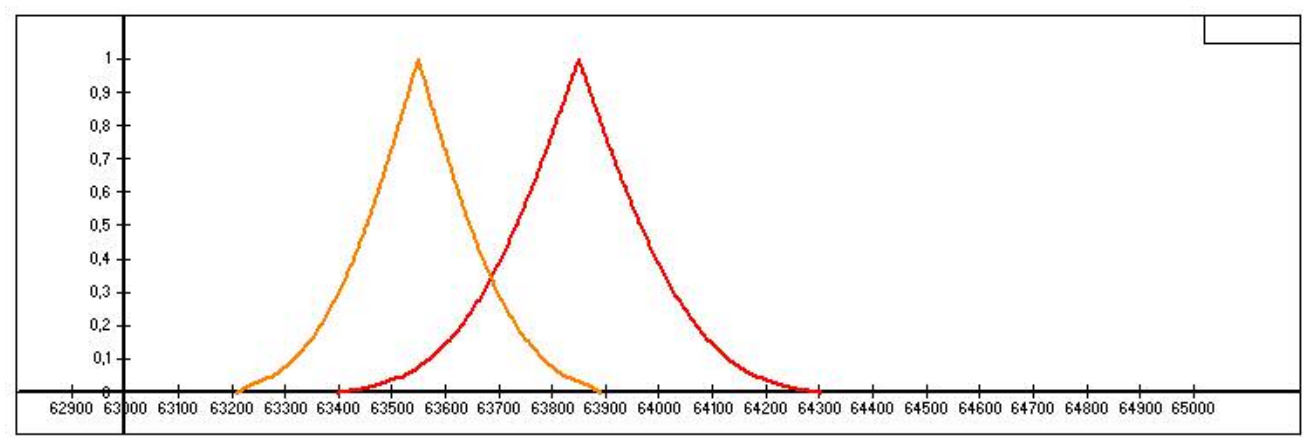




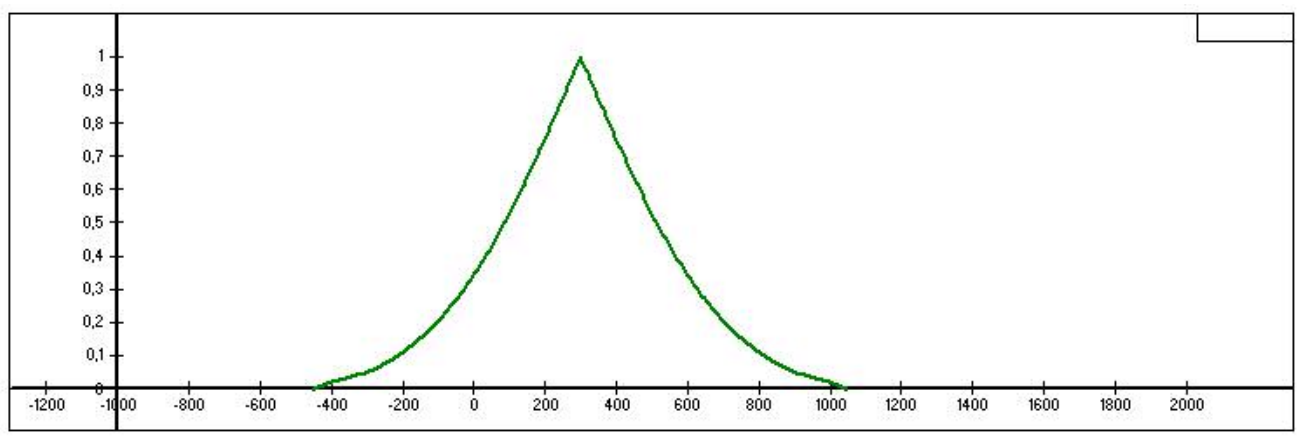

http://mc.manuscriptcentral.com/tprs Email: ijpr@lboro.ac.uk 


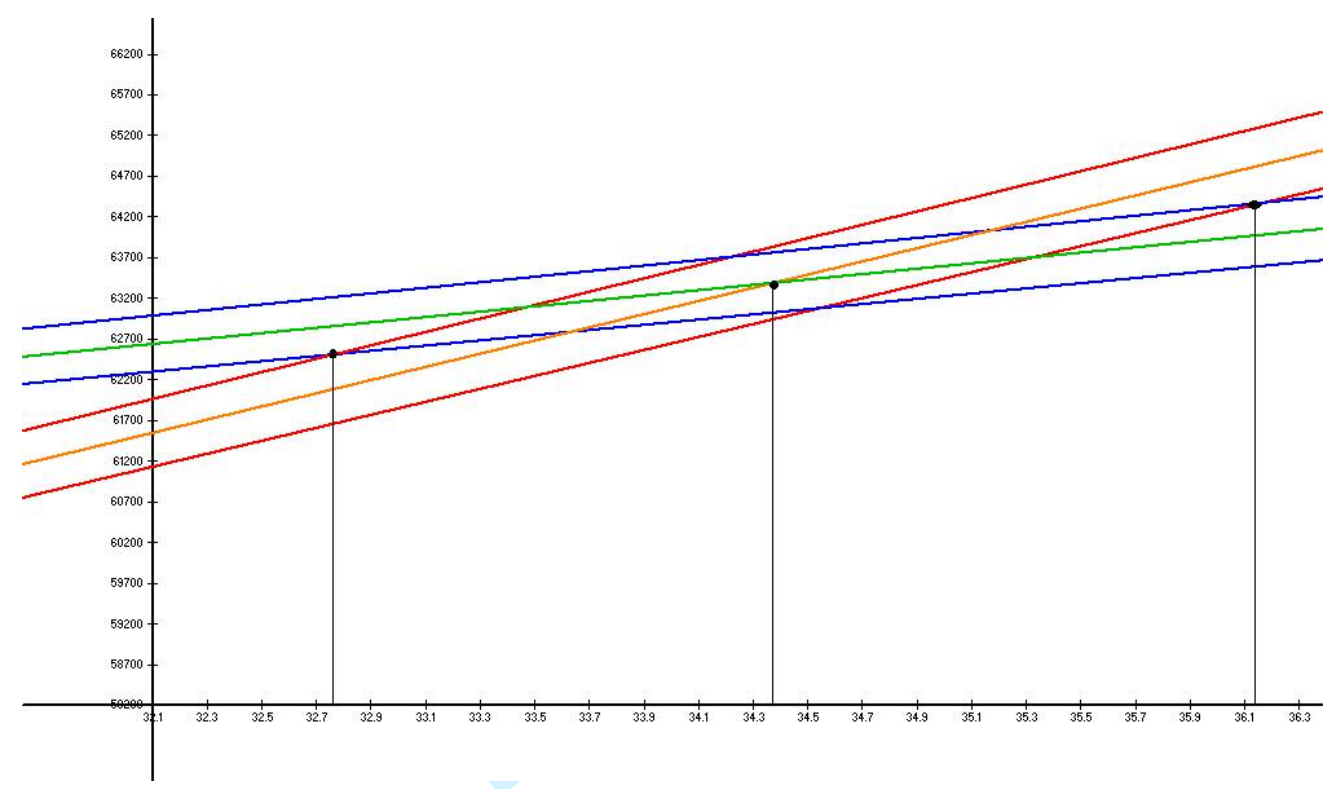



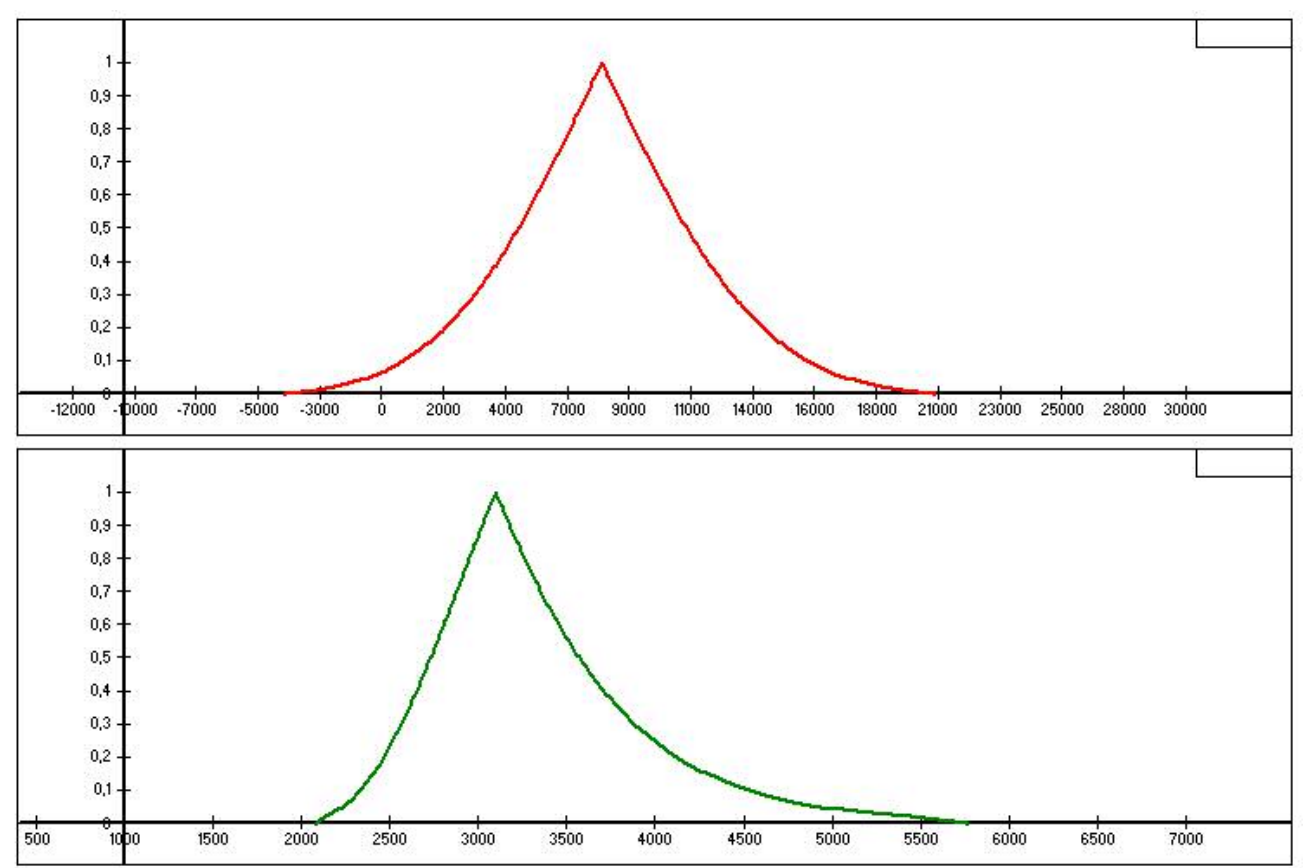

http://mc.manuscriptcentral.com/tprs Email: ijpr@lboro.ac.uk 

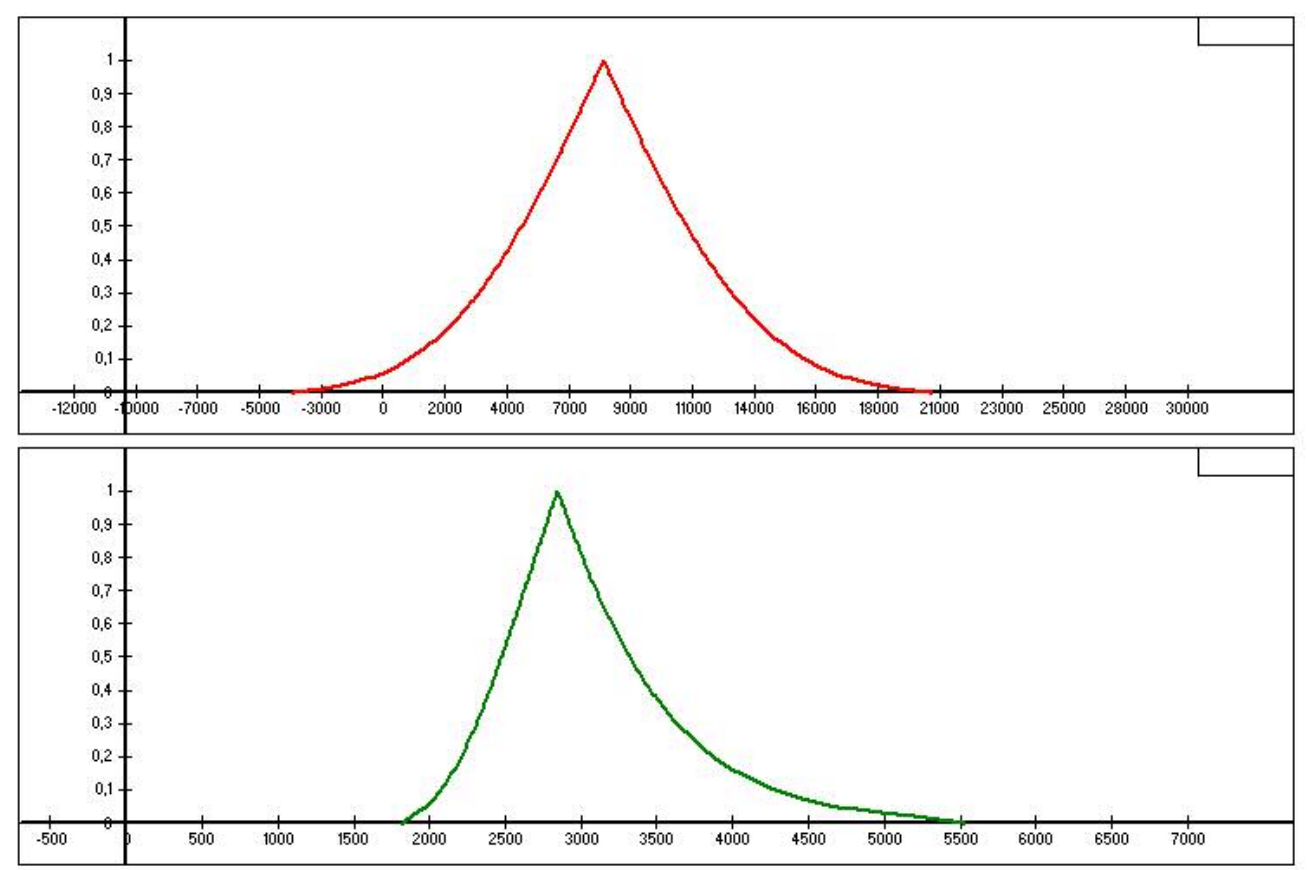

http://mc.manuscriptcentral.com/tprs Email: ijpr@lboro.ac.uk 


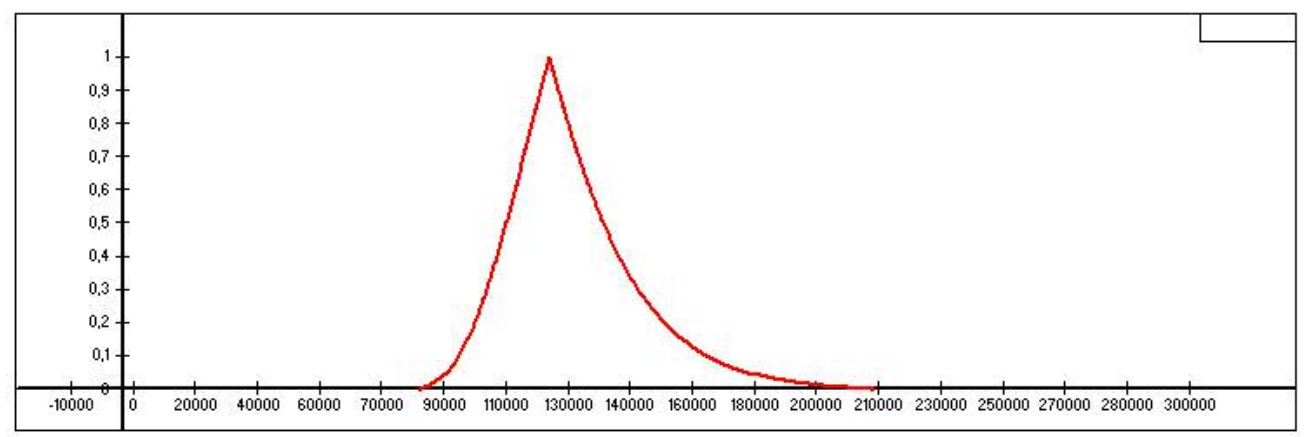

http://mc.manuscriptcentral.com/tprs Email: ijpr@lboro.ac.uk 


\begin{tabular}{|c|c|c|c|c|}
\hline $\mathrm{n}$ & memebership grade & \multicolumn{3}{|c|}{ difference $\mathrm{D}(\mathrm{n})=\mathrm{x}$} \\
\hline \multirow[t]{2}{*}{25} & 0 & -5090.23 & & -3909.77 \\
\hline & 1 & & -4500 & \\
\hline \multirow[t]{2}{*}{26} & 0 & -4633.84 & & -3406.16 \\
\hline & 1 & & -4020 & \\
\hline \multirow{2}{*}{27} & 0 & -4177.45 & & -2902.55 \\
\hline & 1 & & -3540 & \\
\hline \multirow[t]{2}{*}{28} & 0 & -3271.06 & & -2398.94 \\
\hline & 1 & & -3060 & \\
\hline \multirow[t]{2}{*}{29} & 0 & -3264.67 & & -1895.33 \\
\hline & 1 & & -2580 & \\
\hline \multirow[t]{2}{*}{30} & 0 & -2808.28 & & -1391.72 \\
\hline & 1 & & -2100 & \\
\hline \multirow[t]{2}{*}{31} & 0 & -2351.89 & & -888.11 \\
\hline & 1 & & -1620 & \\
\hline \multirow[t]{2}{*}{32} & 0 & -1895.5 & & -384.5 \\
\hline & 1 & & -1140 & \\
\hline \multirow[t]{2}{*}{33} & 0 & -1439.11 & & 119.11 \\
\hline & 1 & & -660 & \\
\hline \multirow[t]{2}{*}{34} & 0 & -982.72 & & 622.72 \\
\hline & 1 & & -180 & \\
\hline \multirow[t]{2}{*}{35} & 0 & -526.33 & & 1126.33 \\
\hline & 1 & & 300 & \\
\hline \multirow[t]{2}{*}{36} & 0 & -69.93 & & 1629.93 \\
\hline & 1 & & 780 & \\
\hline \multirow[t]{2}{*}{37} & 0 & 386.46 & & 2133.54 \\
\hline & 1 & & 1260 & \\
\hline \multirow[t]{2}{*}{38} & 0 & 842.85 & & 2637.15 \\
\hline & 1 & & 1740 & \\
\hline \multirow[t]{2}{*}{39} & 0 & 1299.24 & & 3140.76 \\
\hline & 1 & & 2220 & \\
\hline \multirow[t]{2}{*}{40} & 0 & 1753.63 & & 3644.37 \\
\hline & 1 & & 2700 & \\
\hline 41 & 0 & 2212.02 & & 4147.98 \\
\hline & 1 & & 3180 & \\
\hline 42 & 0 & 2668.41 & & 4651.59 \\
\hline & 1 & & 3660 & \\
\hline 43 & 0 & 3124.8 & & 5155.2 \\
\hline & 1 & & 4140 & \\
\hline 44 & 0 & 3581.19 & & 5658.81 \\
\hline & 1 & & 4620 & \\
\hline 45 & 0 & 4037.58 & & 6162.42 \\
\hline & 1 & & 5100 & \\
\hline 46 & 0 & 4493.97 & & 6666.03 \\
\hline & 1 & & 5580 & \\
\hline 47 & 0 & 4950.36 & & 7169.64 \\
\hline & 1 & & 6060 & \\
\hline 48 & 0 & 5406.75 & & 7673.25 \\
\hline & 1 & & 6540 & \\
\hline 49 & 0 & 5863.14 & & 8176.86 \\
\hline & 1 & & 7020 & \\
\hline 50 & 0 & 6319.53 & & 8680.47 \\
\hline & 1 & & 7500 & \\
\hline 51 & 0 & 6775.93 & & 9184.07 \\
\hline & 1 & & 7980 & \\
\hline 52 & 0 & 7232.32 & & 9687.68 \\
\hline & 1 & & 8640 & \\
\hline 53 & 0 & 7688.71 & & 10191.29 \\
\hline & 1 & & 8940 & \\
\hline
\end{tabular}

Table 1: Some membership grades for different volumes. 